\title{
Thermal denaturation of DNA G- Quadruplexes and their complexes with ligands: thermodynamic analysis of the multiple states revealed by mass spectrometry
}

\author{
Journal Article \\ Author(s): \\ Marchand, Adrien Henri (D); Rosu, Frédéric; Zenobi, Renato (D); Gabelica, Valérie \\ Publication date: \\ 2018-10-03
}

Permanent link:

https://doi.org/10.3929/ethz-b-000291141

Rights / license:

In Copyright - Non-Commercial Use Permitted

Originally published in:

Journal of the American Chemical Society 140(39), https://doi.org/10.1021/jacs.8b07302

Funding acknowledgement:

178765 - Soft ionization mass spectrometry for studying noncovalent interactions (SNF) 


\section{Thermal Denaturation of DNA G-Quadruplexes and}

\section{their Complexes with Ligands: Thermodynamic}

\section{Analysis of the Multiple States Revealed by Mass}

\section{Spectrometry}

Adrien Marchand ${ }^{1}$, Frédéric Rosu $^{2}$, Renato Zenobi $^{1 *}$, Valérie Gabelica $^{2 *}$

${ }^{1}$ Department of Chemistry and Applied Biosciences, ETH Zurich, CH-8093 Zurich, Switzerland

${ }^{2}$ Université de Bordeaux, INSERM U1212, CNRS UMR 5320, ARNA Laboratory, IECB, F-33600

Pessac, France

* Address correspondence to Renato Zenobi (zenobi@org.chem.ethz.ch) or Valérie Gabelica (v.gabelica@iecb.u-bordeaux.fr). 


\section{ABSTRACT}

Designing ligands targeting G-quadruplex nucleic acid structures and affect cellular processes is complicated because there are multiple target sequences and some are polymorphic. Further, structure alone does not reveal the driving forces for ligand binding. To know why a ligand binds, the thermodynamics of binding must be characterized. Electrospray mass spectrometry enables one to detect and quantify each specific stoichiometry (number of strands, cations and ligands) and thus to simultaneously determine the equilibrium formation constants for each complex. Using a temperaturecontrolled nano-electrospray source, we determined the temperature dependence of the equilibrium constants, and thus the enthalpic and entropic contributions to the formation of each stoichiometric state. Enthalpy drives the formation of each quartet- $\mathrm{K}^{+}$-quartet unit, whereas entropy drives the formation of quartet- $\mathrm{K}^{+}$-triplet units. Consequently, slip-stranded structures can become more abundant as the temperature increases. In presence of ligands (Phen-DC3, TrisQ, TMPyP4, Cu-ttpy), we observed that even when only a 1:1 (ligand:quadruplex) complex is observed at room temperature, new states are populated at intermediate temperatures, including 2:1 complexes. In most cases, ligand-G4 binding is entropically driven, and we discuss that this may have resulted from biases when ranking ligand potency using melting experiments. Other thermodynamic profiles could be linked to topology changes in terms of number of G-quartets, which is reflected in the number of specific $\mathrm{K}^{+}$ions in the complex. The thermodynamics of ligand binding to each form, one ligand at a time, provides unprecedented detail on the interplay between ligand binding and topology changes in terms of number of G-quartets. 


\section{INTRODUCTION}

Besides storing genetic information, nucleic acids are also involved in the regulation of gene expression. To ensure such function, they adopt particular three-dimensional structures, one of which being the Gquadruplex: ${ }^{1}$ a four-stranded assembly made of stacked guanine quartets. The quartets are stabilized by hydrogen bonds between the bases, and their stacking is further stabilized by monovalent cation coordination in-between the G-quartets. The existence of DNA G-quadruplex structures in cells was revealed thanks to antibodies. ${ }^{2}$ Owing to their prevalence in telomeres and oncogene promoters, Gquadruplexes became attractive targets for anti-cancer therapies. ${ }^{3,45-7}$ One strategy consists in developing synthetic ligands able to displace the folding equilibria towards the G-quadruplex structure to either hamper telomere maintenance or downregulate oncoproteins. Characterizing the binding affinity, structural selectivity, and G-quadruplex stabilization properties of small molecule ligands is thus of prime interest.

X-ray crystallography ${ }^{8}$ and nuclear magnetic resonance (NMR $)^{9,10}$ are powerful techniques to determine the structure of complexes, but are difficult to apply to polymorphic targets such as the human telomeric sequence (TTAGGG repeats). ${ }^{11}$ To date, six distinct topologies were solved for the target sequences $\mathrm{N}_{\mathrm{i}} \mathrm{GGG}(\mathrm{TTAGGG})_{3} \mathrm{~N}_{\mathrm{j}}$, depending on the cation and on the choice of overhangs $\mathrm{N}_{\mathrm{i}}$ and $\mathrm{N}_{\mathrm{j}}$. The sequence 22AG (see Table 1) forms an antiparallel 3-quartet structure in sodium solution, ${ }^{12}$ a parallel 3-quartet structure in potassium crystals, ${ }^{13}$ and a mixture of at least three different other structures in potassium solutions: the 3-quartet hybrid-1 (solved by NMR for $24 \mathrm{TTG}^{14}$ and $23 \mathrm{TAG}^{15}$ ) and hybrid-2 structures ${ }^{16}$ and one antiparallel 2-quartet structure with slipped strands (solved for $22 \mathrm{GT}^{17}$ ). Most structures available for ligand complexes with intramolecular telomeric G-quadruplexes were solved by X-ray crystallography, and the only complexes solved by $\mathrm{NMR}^{16,18,19}$ in potassium were cases where the ligand did not significantly affect the topology, i.e. the arrangement of the G-quadruplex stem.

The scarcity of structural information about ligand binding necessitates to rely heavily on biophysical characterization. Moreover, besides structure, the equilibrium binding constants are the key determinants for the ligand potency, either as a drug or as an artificial probe. Ligand binding constants are determined from isothermal titration experiments, which can be monitored using ligand spectroscopic properties, surface plasmon resonance (SPR),${ }^{20}$ or calorimetry (ITC) ${ }^{21}$ Another popular method is to monitor a physical property of the folded state as a function of a perturbation such as temperature, ${ }^{22-24}$ and compare the effects in absence and presence of ligand. For G-quadruplexes, thermal denaturation ${ }^{25}$ can be monitored by UV absorption at $295 \mathrm{~nm},{ }^{26}$ by circular dichroism (CD) at wavelengths characteristic of homo-stacking $(260 \mathrm{~nm})$ and hetero-stacking $(295 \mathrm{~nm})$ of guanines, ${ }^{27,28}$ by Förster resonance energy 
transfer between chromophores grafted on strand extremities, ${ }^{25}$ by NMR, or by differential scanning calorimetry (DSC). ${ }^{29}$ The temperature at which half of the population is unfolded is called the melting temperature $\left(T_{\mathrm{m}}\right)$, and the difference of melting temperature in presence and absence of ligand $\left(\Delta T_{\mathrm{m}}\right)$ often provides the first ranking when screening ligand libraries for their potential to stabilize G-quadruplexes.

Table 1. Abbreviations, sequences, structures and PDB codes of the G-quadruplexes studied here.

\begin{tabular}{|c|c|c|c|}
\hline Abbreviation & Sequence & Structure obtained by NMR in $100 \mathrm{mM} \mathrm{K} \mathrm{K}^{+}$ & PDB ID \\
\hline $24 \mathrm{TTG}$ & d(TT(GGGTTA) ${ }_{3}$ GGGA) & $\begin{array}{llll}\begin{array}{l}\text { Monomorphic } \\
\text { quadruplex }\end{array} & \text { Hybrid-1 } & \text { (3-tetrad) } & \text { G- } \\
\end{array}$ & $2 \mathrm{GKU}^{14}$ \\
\hline $22 \mathrm{AG}$ & $\mathrm{d}\left(\mathrm{A}(\mathrm{GGGTTA})_{3} \mathrm{GGG}\right)$ & $\begin{array}{l}\text { Mixture of at least three G-quadruplex } \\
\text { structures (hybrid-1, hybrid-2 and antiparallel } \\
\text { 2-tetrad) }\end{array}$ & \\
\hline $22 \mathrm{GT}$ & $\mathrm{d}\left((\text { GGGTTA })_{3}\right.$ GGGT $)$ & Mainly antiparallel 2-tetrad G-quadruplex & $2 \mathrm{KF}^{17}$ \\
\hline 23TAG & $\mathrm{d}\left(\mathrm{TA}(\mathrm{GGGTTA})_{3} \mathrm{GGG}\right)$ & Mainly hybrid-1 G-quadruplex & $2 \mathrm{JSM}^{15}$ \\
\hline $22 \mathrm{CTA}$ & $\mathrm{d}\left(\mathrm{A}(\mathrm{GGGCTA})_{3} \mathrm{GGG}\right)$ & $\begin{array}{l}\text { Antiparallel quadruplex with } 2 \text { G-tetrads and } \\
\text { one G:C:G:C tetrad }\end{array}$ & $2 \mathrm{KM} 3^{30}$ \\
\hline 1XAV & $\begin{array}{l}\text { d(TGA GGG TGG GTA } \\
\text { GGG TGG GTA A) }\end{array}$ & Monomorphic parallel 3-tetrad G-quadruplex & $1 \mathrm{XAV}^{31}$ \\
\hline $\mathrm{T} 95-2 \mathrm{~T}$ & $\mathrm{~d}\left(\mathrm{TT}(\mathrm{GGGT})_{4}\right)$ & Monomorphic parallel 3-tetrad G-quadruplex & $2 \mathrm{LK} 7^{32}$ \\
\hline
\end{tabular}

Thermal denaturation data and isothermal titration data do however not always agree, mainly because different states can be populated at different temperatures. In UV-melting or FRET-melting, for example, only one signal is monitored and thus a two-state model often has to be assumed. ${ }^{33}$ Deconvolution of multi-wavelength circular dichroism (CD-melting) signals showed that G-quadruplex melting, without ligand, is not two-state. ${ }^{34-36}$ The same was found with DSC. ${ }^{37}$

With ligands, the situation is expected to become even more complex, because some ligands are able to change the G-quadruplex topology. For example, the selective and high-affinity telomeric ligand PhenDC3 conformationally selects a 2 -quartet antiparallel structure, ${ }^{38}$ and the $\mathrm{Cu}(\mathrm{II})$-tolylterpyridine selects a 3-quartet antiparallel chair structure upon cooperative binding of two ligands. ${ }^{39}$ These conclusions were based on isothermal titrations monitored by $\mathrm{CD}$ and native electrospray mass spectrometry (MS).

The strength of native MS is to unambiguously detect and quantify each of the multiple stoichiometries coexisting in a mixture. In the case of ligand binding to G-quadruplexes, the stoichiometry of each strand:cation:ligand ternary complex $\left(\mathrm{M}_{\mathrm{n}} \mathrm{K}_{\mathrm{i}} \mathrm{L}_{\mathrm{j}}\right)$ can be determined unambiguously. ${ }^{40}$ In G-quadruplexes, the number $i$ of specifically bound $\mathrm{K}^{+}$ions informs us on the number of stacked G-quartets $(i+1)$, and the 
$\mathrm{K}^{+}$binding is thus a proxy for G-quadruplex folding. Based on $\mathrm{K}^{+}$binding, we recently studied Gquadruplex folding pathways ${ }^{41}$ and demonstrated that $1-\mathrm{K}^{+} / 2$-quartet antiparallel G-quadruplexes form at low $\mathrm{K}^{+}$concentration or as short-lived misfolded species. In presence of ligands, the number of specifically bound $\mathrm{K}^{+}$ions indicates whether the complex is unfolded $\left(0 \mathrm{~K}^{+}\right)$, has two G-quartets $\left(1 \mathrm{~K}^{+}\right)$ or three G-quartets $\left(2 \mathrm{~K}^{+}\right)$. Thus, if up to two ligands can bind per G-quadruplex, up to nine states can be readily separated by native MS (Figure 1), and quantified based on the signal intensities ${ }^{42}$ to determine equilibrium binding constants and thus $\Delta \mathrm{G}^{\circ}$ of complex formation.

Here, we examined how these binding constants change with the solution temperature. To do so, we built a temperature-variable nanoelectrospray source, inspired by previous designs. ${ }^{43-46}$ The nanospray emitter is embedded inside a temperature-controlled copper block (Figure S 1). MS-melting experiments, i.e. the quantitation of each stoichiometry as a function of the solution temperature, allows a thorough thermodynamic characterization of binding enthalpies $\left(\Delta \mathrm{H}^{\circ}\right)$ and entropies $\left(\Delta \mathrm{S}^{\circ}\right)$, and we will show how these thermodynamic parameters can be interpreted in terms of structure.

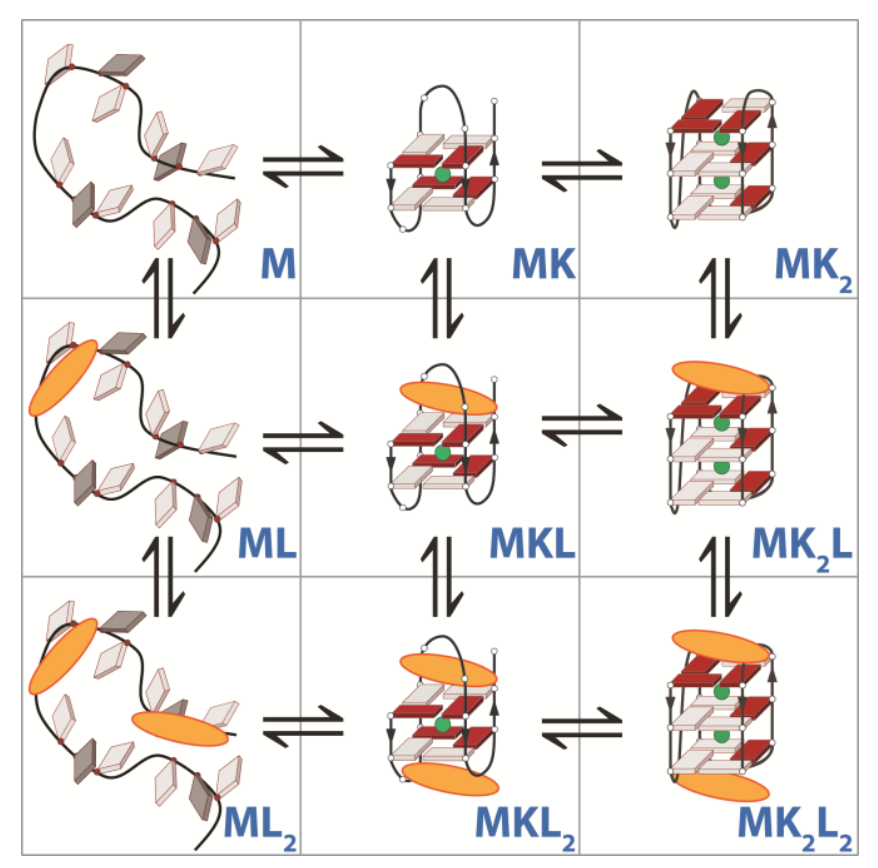

Figure 1. Chemical equilibria for ligand binding to a G-quadruplex forming sequence. Ligand $\mathrm{L}$ is in yellow, and potassium ions $(\mathrm{K})$ are in green. G-quadruplexes require at least one potassium ion to fold.

\section{RESULTS}

\section{Thermal denaturation of G-quadruplexes}

First, we monitored the thermal denaturation of human telomeric G-quadruplexes, without ligands, using CD and native MS. The sequences studied here are listed in Table 1. The CD-melting of 24TTG in $100 \mathrm{mM}$ trimethylammonium acetate (TMAA) and $1 \mathrm{mM} \mathrm{KCl}$ is shown in Figure 2. The apparent melting temperature depends on the chosen wavelength. At $290 \mathrm{~nm}$ (Figure 2C, black symbols), a wavelength 
monitoring alternate (anti-syn and syn-anti) stacking between adjacent G-quartets, the melting curve is sigmoidal with a $T_{\mathrm{m}}=40^{\circ} \mathrm{C}$. The inflexion point corresponds to a drop of signal by one half. In contrast, at $260 \mathrm{~nm}$ (Figure 2D, black symbols), a wavelength characteristic of homo-stacking (anti-anti), the CD signal is constant up to $\sim 40{ }^{\circ} \mathrm{C}$, then decreases monotonically, preventing one to accurately determine a melting temperature. The temperature of signal half-drop $\left(T_{1 / 2}\right)$ is $54{ }^{\circ} \mathrm{C}$. Clearly, more than two states are populated during the thermal unfolding, as also suggested by the absence of isodichroic point in Figure 2A. The presence of intermediates, assigned to parallel structures based on the CD signal at $260 \mathrm{~nm}$, was previously reported by Chaires and coworkers. ${ }^{35}$

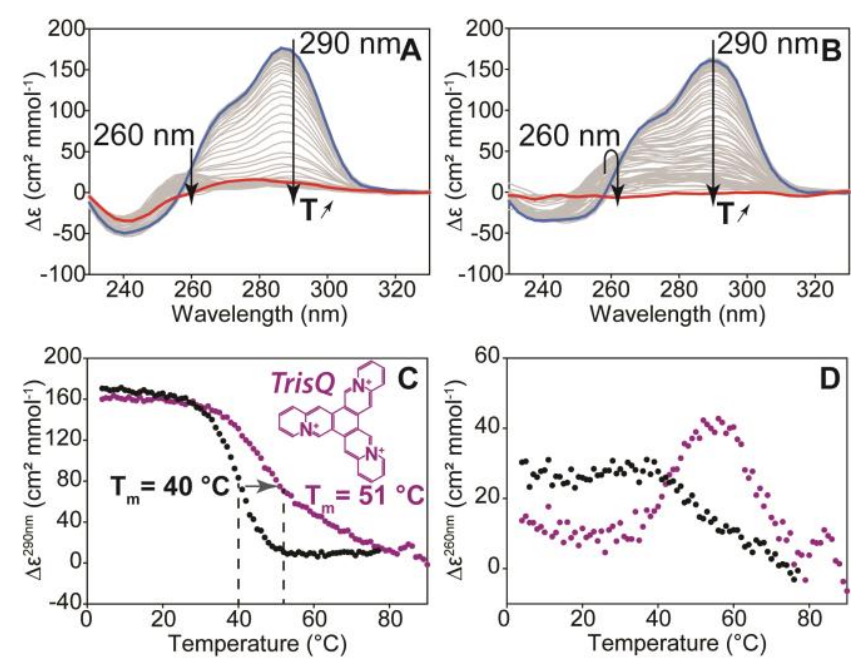

Figure 2. CD-melting of 24TTG (d(TT(GGGTTA) $)_{3}$ GGGA)) in $100 \mathrm{mM}$ TMAA and $1 \mathrm{mM} \mathrm{KCl}$, without ligand (A) and with one equivalent TrisQ (B). A-B: full CD traces from $4{ }^{\circ} \mathrm{C}$ (blue) to $78^{\circ} \mathrm{C}$ (A) or $90^{\circ} \mathrm{C}$ (B) (red). Traces at intermediate temperatures are in grey. C-D: Extracted molar circular dichroic signal as a function of temperature for $24 \mathrm{TTG}\left(\mathrm{d}\left(\mathrm{TT}(\mathrm{GGGTTA})_{3} \mathrm{GGGA}\right)\right.$ ) alone (black) or with one equivalent TrisQ (purple) at $290 \mathrm{~nm}(\mathrm{C})$ and $260 \mathrm{~nm}(\mathrm{D})$.

We then monitored the thermal denaturation by native mass spectrometry (Figure 3). At $26^{\circ} \mathrm{C}$ in $1 \mathrm{mM}$ $\mathrm{KCl}, 24 \mathrm{TTG}$ (Figure 3A and Figure S 3) binds exclusively two specific $\mathrm{K}^{+}$ions, indicating that a 3-quartet G-quadruplex is fully formed. When the temperature is increased, the $\mathrm{MK}_{2}$ complex disappears and the potassium-free, unfolded state $(\mathrm{M})$ appears. A peak corresponding to the MK stoichiometry is visible, but after correcting for the intensity of nonspecific adducts on M (see experimental details), the abundance of specific MK complex is negligible at all temperatures. The abundances of specific $\mathrm{M}$ and $\mathrm{MK}_{2}$ complexes are then calculated from the intensities, and plotted as a function of temperature (Figure 3B). The melting temperature $(50 \%$ of unfolded form $\mathrm{M})$ is $46{ }^{\circ} \mathrm{C}$. Only two states can be distinguished based on stoichiometry, suggesting that the additional minor states suggested by $\mathrm{CD}$ have a potassium binding 
stoichiometry of either $0 \mathrm{~K}^{+}$or $2 \mathrm{~K}^{+}$. Ion mobility separation did not reveal any significant change of the conformational population under each stoichiometry (Figure S 2).
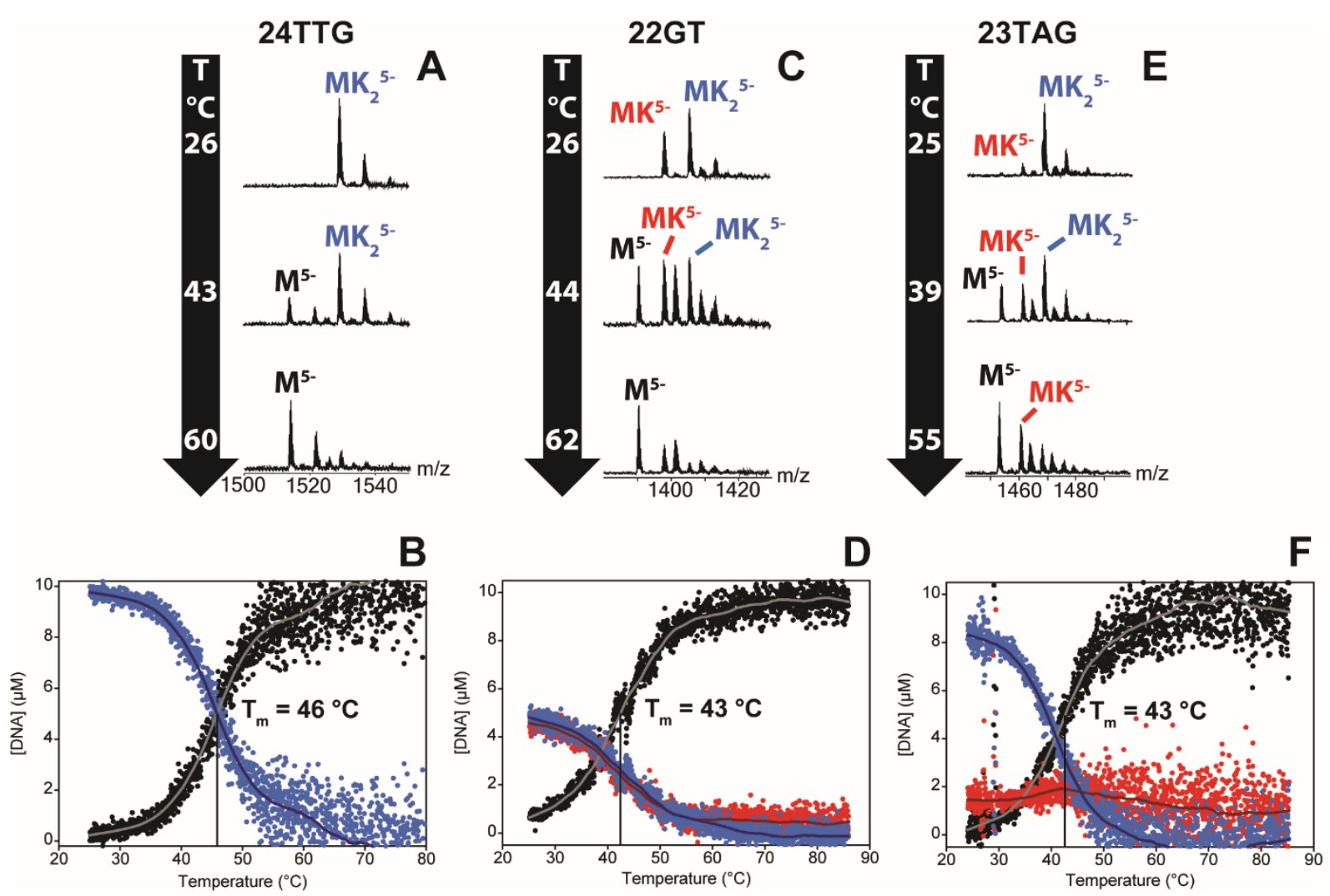

Figure 3. Thermal denaturation experiment monitored using MS of $10 \mu \mathrm{M}$ 24TTG (A-B), 22GT (C-D) and 23TAG (E-F) in $100 \mathrm{mM}$ TMAA and $1 \mathrm{mM} \mathrm{KCl}$. A, C and E are representative mass spectra of the melting experiment, obtained at the temperature indicated in the black arrows. B, D and F are obtained after quantifying each of the stoichiometry as a function of time and after subtracting the nonspecific adducts contributions (see experimental section).

We also performed MS-melting experiments on telomeric sequences that bind potassium ions less cooperatively than $24 \mathrm{TTG}$, i.e. for which the $1-\mathrm{K}^{+}$complex is observable. The sequence $22 \mathrm{GT}$ forms both $\mathrm{MK}$ and $\mathrm{MK}_{2}$ complexes at room temperature in $1 \mathrm{mM} \mathrm{KCl}$. $\mathrm{MK}$ and $\mathrm{MK}_{2}$ disappear concertedly upon increasing temperature (Figure 3B and Figure S 4). The MS-melting temperature is the same for both stoichiometries $\left(43^{\circ} \mathrm{C}\right)$ and is also very close to the one obtained by CD-melting. ${ }^{38}$ The sequence 23TAG folds into a hybrid-1 G-quadruplex very similar to $24 \mathrm{TTG}$ in $100 \mathrm{mM} \mathrm{K}$, but can also form a $1-\mathrm{K}^{+} / 2-$ quartet antiparallel structure at lower $\mathrm{KCl}$ concentrations. ${ }^{41}$ At room temperature in $1 \mathrm{mM} \mathrm{KCl}$, the $\mathrm{MK}_{2}$ complex predominates (Figure 3C and Figure $\mathrm{S} 5$ ). When the temperature is increased, the $\mathrm{MK}_{2}$ complex disappears, but some MK complex, even after subtraction of the contribution of nonspecific adducts to the peak area, remains present and even slightly increases in abundance above $35^{\circ} \mathrm{C}$. The MK complex thus qualifies as a thermal denaturation intermediate. The melting temperature $(50 \%$ of $\mathrm{M})$ is $43{ }^{\circ} \mathrm{C}$. The 
comparison between 23TAG and 22GT illustrate that very different denaturation mechanisms can be hidden behind identical $T_{\mathrm{m}}$ values.

Results obtained with other human telomeric G-quadruplex forming sequences (22AG and 22CTA) and for two parallel-stranded 3-quartet G-quadruplexes (the c-myc promoter 1XAV and the synthetic sequence T95-2T) are also shown in supporting information (respectively in Figure S 6, Figure S 7, Figure S 8 and Figure S 9). 22AG behaves similarly to 22GT (see more in the discussion section), 22CTA binds only $1 \mathrm{~K}^{+}$ion specifically, and the parallel sequences bind exclusively, and cooperatively, $2 \mathrm{~K}^{+}$ions. No intermediate of peculiar $\mathrm{K}^{+}$binding stoichiometry was observed in those cases.

\section{Thermodynamics of $\mathrm{K}^{+}$binding to G-quadruplexes}

The quantification of each specific complex at each temperature from the peak areas allows one to calculate the equilibrium association constants, and thus the Gibbs free energy at each temperature. Then, using Van't Hoff plots, the enthalpic and entropic contributions can be determined. The values obtained from the MS-melting experiments are reported in Table 2.

Table 2. Thermodynamic parameters of potassium binding to G-quadruplex forming sequences (the standard state refers to $1 \mathrm{M}$ reactants and products, in $100 \mathrm{mM}$ TMAA solution conditions).

\begin{tabular}{|c|c|c|c|c|c|c|c|c|c|}
\hline & \multirow{2}{*}{$\begin{array}{l}{ }^{\mathrm{MS}} T_{\mathrm{m}}(50 \% \\
\mathrm{M}) \text { in } 1 \mathrm{mM} \\
\mathrm{KCl} \text { and } 100 \\
\mathrm{mM} \text { TMAA } \\
\left({ }^{\circ} \mathrm{C}\right)\end{array}$} & \multicolumn{2}{|c|}{$\begin{array}{c}\Delta \boldsymbol{G}^{\circ}(\mathbf{2 9 8 K}) \\
(\mathrm{kcal} / \mathrm{mol})\end{array}$} & \multicolumn{2}{|c|}{$\begin{array}{c}\Delta \boldsymbol{H}^{\circ} \\
(\mathrm{kcal} / \mathrm{mol})\end{array}$} & \multicolumn{2}{|c|}{$\begin{array}{c}\Delta \boldsymbol{S}^{\circ} \\
(\mathrm{cal} /(\mathrm{mol} . \mathrm{K}))\end{array}$} & \multicolumn{2}{|c|}{$\begin{array}{l}-298 \Delta S^{\circ} \\
(\mathrm{kcal} / \mathrm{mol})\end{array}$} \\
\hline & & $\mathrm{M}+\mathrm{K} \stackrel{\leftrightarrows}{\leftrightarrows} \mathrm{MK}$ & $\mathrm{M}+2 \mathrm{~K} \leftrightarrows \mathrm{MK}_{2}$ & $\mathrm{M}+\mathrm{K} \stackrel{\leftarrow}{\leftrightarrows} \mathrm{MK}$ & $\mathrm{M}+2 \mathrm{~K} \leftrightarrows \mathrm{MK}_{2}$ & $\mathrm{M}+\mathrm{K} \stackrel{\leftarrow}{\leftrightarrows} \mathrm{MK}$ & $\mathrm{M}+2 \mathrm{~K} \leftrightarrows \mathrm{MK}_{2}$ & $\mathrm{M}+\mathrm{K} \stackrel{\leftrightarrows}{\leftrightarrows} \mathrm{MK}$ & $\mathrm{M}+2 \mathrm{~K} \stackrel{\leftrightarrows}{\leftrightarrows} \mathrm{MK}_{2}$ \\
\hline 1XAV & 60 & & $-14.5 \pm 1.5^{c}$ & & $-60.1 \pm 0.8^{a}$ & & $-153.1 \pm 2.3^{\mathrm{a}}$ & & $45.6 \pm 0.7^{\mathrm{a}}$ \\
\hline T95-2T & 65 & & $-15.3 \pm 1.5^{c}$ & & $-55 \pm 0.8^{\mathrm{a}}$ & & $-135.2 \pm 2.3^{\mathrm{a}}$ & & $40.3 \pm 0.7^{\mathrm{a}}$ \\
\hline 24TTG & 46 & & $-11.48 \pm 0.10^{\mathrm{b}}$ & & $-53 \pm 3^{b}$ & & $-140 \pm 10^{\mathrm{b}}$ & & $42 \pm 3^{\mathrm{b}}$ \\
\hline 23TAG & 43 & $-4.9 \pm 1.3^{c}$ & $-10.3 \pm 2.1^{\mathrm{c}}$ & $-25.3 \pm 0.7^{\mathrm{a}}$ & $-43 \pm 1^{a}$ & $-68.3 \pm 2.1^{\mathrm{a}}$ & $-109 \pm 4^{\mathrm{a}}$ & $20.4 \pm 0.6^{\mathrm{a}}$ & $32.5 \pm 1.1^{\mathrm{a}}$ \\
\hline 22GT & 43 & $-5.32 \pm 0.09^{b}$ & $-9.4 \pm 0.2^{\mathrm{b}}$ & $-32 \pm 3^{b}$ & $-30.5 \pm 1.8^{b}$ & $-89 \pm 9^{b}$ & $-71 \pm 5^{b}$ & $26 \pm 3^{\mathrm{b}}$ & $21.1 \pm 1.6^{\mathrm{b}}$ \\
\hline $22 \mathrm{AG}$ & 35 & $-5.2 \pm 0.6^{\mathrm{b}}$ & $-9.2 \pm 0.7^{b}$ & $-28 \pm 3^{\mathrm{b}}$ & $-31 \pm 3^{b}$ & $-75 \pm 9^{b}$ & $-72 \pm 7^{b}$ & $22 \pm 3^{\mathrm{b}}$ & $21.4 \pm 2.2^{\mathrm{b}}$ \\
\hline 22CTA & 34 & $-4.7 \pm 1.0^{c}$ & & $-21.7 \pm 0.5^{a}$ & & $-56.9 \pm 1.7^{\mathrm{a}}$ & & $17 \pm 0.5^{\mathrm{a}}$ & \\
\hline
\end{tabular}

${ }^{\mathrm{a}}$ Uncertainty $=$ standard deviation from the fit of the Van't Hoff plot.

${ }^{\mathrm{b}}$ Uncertainty $=$ standard deviation of multiple experiments.

${ }^{\mathrm{c}}$ Uncertainty given by the propagation of the standard deviation from the fit of the Van't Hoff plot.

G-quadruplex formation is enthalpically favorable $\left(\Delta H_{\text {assn }}^{\circ}<0\right)$ and entropically unfavorable $\left(\Delta S_{\text {assn }}^{\circ}<\right.$ 0 ) in all cases. ${ }^{47-49}$ This is in line with what happens to the DNA sequence: the entropically unfavorable stiffening of the structure is compensated by the enthalpically favorable hydrogen bond formation, stacking interactions, and cation coordination. These effects thus seem to predominate compared to the 
entropically-favorable solvent release from the solvation shell of potassium and/or from the DNA strand upon G-quadruplex formation (the latter being less hydrated than the former ${ }^{50,51}$ ).

In Table 2, the sequences are ordered from the most enthalpically favored $\mathrm{MK}_{2}$ complex to the least favored (22CTA, in which $\mathrm{MK}_{2}$ is not formed). The free energy $\left(\Delta G^{\circ}{ }_{\text {assn }}\right)$ at $298 \mathrm{~K}$ follows the same order. The melting temperatures follow the same trend, except for $1 \mathrm{XAV}$ and T92-2T which are reversed. This means that the entropic contributions differ enough so that the stability order is reversed at $298 \mathrm{~K}$ compared to around their melting temperature (335-340 K).

The parallel G-quadruplexes 1XAV and T95-2T are the most favored, followed very closely by the hybrid-1 G-quadruplex formed by 24TTG, which is the most monomorphic telomeric G-quadruplex sequence variant. 23TAG, which forms predominantly the same hybrid-1 structure, but also a 2-quartet structure MK, comes next. Note that here, the $\mathrm{MK}_{2}$ peak intensity may be the sum of two states: the 3quartet hybrid-1 structure, and the 2-quartet antiparallel structure with one additional potassium ion specifically bound between a G-triplet and a G-quartet. The latter is the major structure of the $\mathrm{MK}_{2}$ complex of $22 \mathrm{GT}^{17}$ The thermodynamic profile of the $\mathrm{MK}_{2}$ complex of $22 \mathrm{AG}$ is very similar to that of 22GT. Finally, the thermodynamic parameters for $1 \mathrm{~K}^{+}$binding to 22CTA, forming exclusively a 2-quartet structure with no additional specific $\mathrm{K}^{+}$binding site, closely resemble those of the MK complex of 23TAG. The structural interpretation of these thermodynamic parameters will be further addressed in the discussion section.

\section{Intermediates in the thermal denaturation of DNA G-quadruplexes with ligands}

The CD-melting of 24TTG in the presence of one equivalent of TrisQ, a high affinity G-quadruplex ligand, ${ }^{52}$ is shown in Figure 2B and Figure S 10). At $290 \mathrm{~nm}$ (Figure 2C, purple symbols), the apparent melting temperature is $51{ }^{\circ} \mathrm{C}$, so the $\Delta T_{\mathrm{m}}$ induced by the ligand is $11^{\circ} \mathrm{C}$. Yet the shape of the melting curve is affected by the presence of the ligand, suggesting the presence of other intermediates and/or a drastic change of the thermodynamic parameters of the unfolding of the complex. Furthermore, other wavelengths give different melting curves (see Figure S 10A) with different melting temperatures. 260 $\mathrm{nm}$ is an extreme case: in the presence of TrisQ (Figure 2D, purple symbols), the CD-melting curve is not sigmoidal and no $T_{m}$ can decently be defined. With the ligand Phen-DC3, the results are highly wavelength-dependent as well (Figure S 10B).

MS-melting helps to disentangle the different states based on their stoichiometry. Figure 4 and Figure S 11 show the MS-melting of 24TTG with one equivalent of TrisQ. At room temperature, the ligand binds by forming mainly a $\mathrm{MK}_{2} \mathrm{~L}$ complex. The 2:1 (ligand:quadruplex) complex is absent, although the hybrid- 
1 structure has two potential end-stacking sites. The low-temperature CD spectrum does not indicate a major rearrangement of 24TTG upon TrisQ binding. This means that the two end-stacking sites are not equivalent. ${ }^{42}$ In addition to the $\mathrm{MK}_{2} \mathrm{~L}$ complex, a minor MKL complex is also present. TrisQ is thus also able to bind to a 2-quartet structural variant and partly displace the initial population (major hybrid-1) towards that structure.
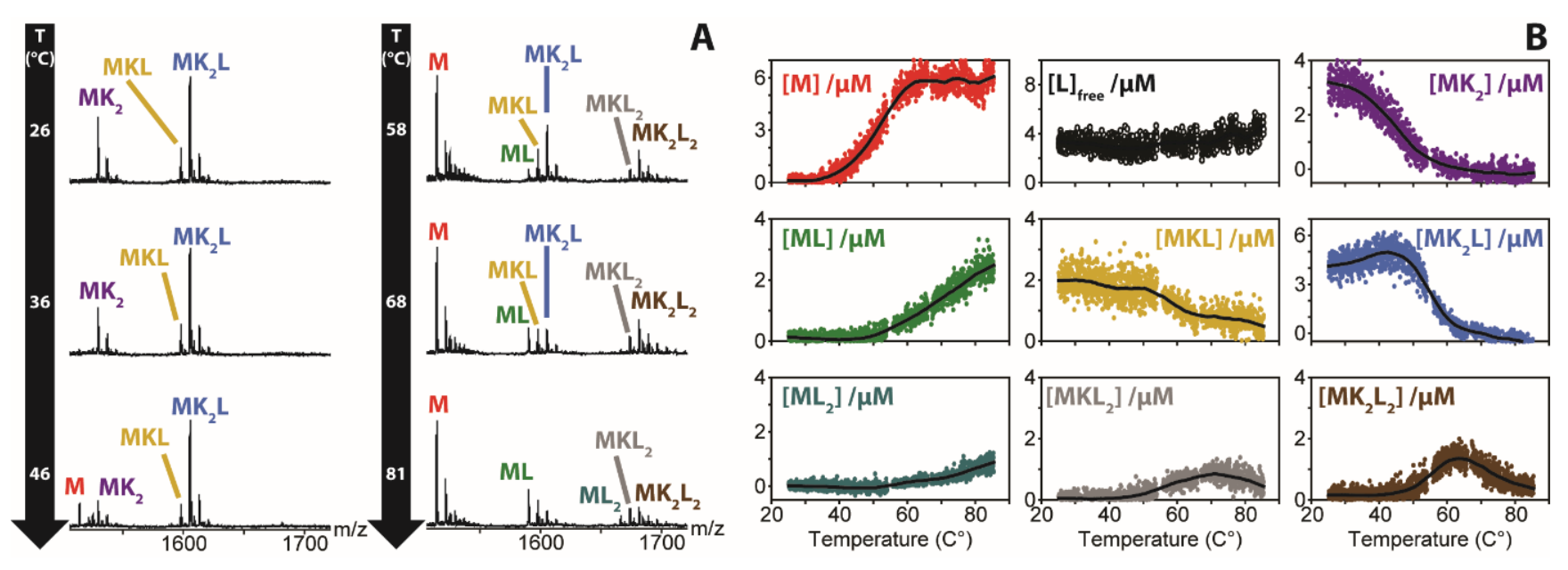

Figure 4. MS-melting of $10 \mu \mathrm{M} 24 \mathrm{TTG}$ with $10 \mu \mathrm{M}$ TrisQ in $100 \mathrm{mM}$ TMAA and $1 \mathrm{mM} \mathrm{KCl}$. A: mass spectra obtained at various temperatures (Zooms on the 5- charge state). B: Quantification of each state distinguished based on its stoichiometry. The concentration of free ligand is obtained by difference.

Upon temperature increase, up to eight states were observed. The sequence of events upon heating is as follows:

1) The $\mathrm{MK}_{2}$ state (3-tetrad G-quadruplex alone) melts at a similar temperature as without ligand ( 46 ${ }^{\circ} \mathrm{C}$ ). This is expected if the experiment reflects equilibria; the only reason for which the structure of the free G-quadruplex would change in presence of ligand would be a slow rearrangement following ligand unbinding. In the range $25-40{ }^{\circ} \mathrm{C}$, the ratio between $\mathrm{MK}_{2} \mathrm{~L}$ and $\mathrm{MK}_{2}$ increases when the temperature increases, indicating that the $\Delta G^{\circ}{ }_{M K_{2}} \rightarrow M K_{2} L$ decreases (ligand binding to $\mathrm{MK}_{2}$ is increasingly favored).

2) The melting temperature of the main complex $\left(\mathrm{MK}_{2} \mathrm{~L}\right)$, defined as the temperature at which half $\mathrm{MK}_{2} \mathrm{~L}$ disappears, is $55^{\circ} \mathrm{C}$. This temperature is in the same range than-but not identical to- the CD-melting $T_{\mathrm{m}}$ deduced at $290 \mathrm{~nm}\left(51^{\circ} \mathrm{C}\right)$.

3) Surprisingly, new states appear after the denaturation of $\mathrm{MK}_{2} \mathrm{~L}$, notably a 3-quartet complex with two bound ligands: $\mathrm{MK}_{2} \mathrm{~L}_{2}$. This counterintuitive result can be explained as follows. At room temperature, the ligand:quadruplex molar ratio is 1:1. However, upon melting of the free Gquadruplex, the ligand:quadruplex molar ratio increases, and TrisQ can thus populate the second 
binding site of the remaining G-quadruplexes. The formation of new complexes as the temperature increases explains why the spectroscopic melting curves are not sigmoidal. It is also possible that some of the high-temperature complexes have a different structure than the room temperature ones. Intriguingly, the $\mathrm{MK}_{2} \mathrm{~L}_{2}$ complex appears at temperatures at which the $\mathrm{CD}$ signal at $260 \mathrm{~nm}$ increases (Figure 2D), and thus the $\mathrm{MK}_{2} \mathrm{~L}_{2}$ complex may contain a higher degree of homo-stacking (typical of parallel-stranded structures). Experiments with T95-2T shows that TrisQ binds to this parallel G-quadruplex with very high affinity and up to 2:1 stoichiometry (Figure S 12).

4) The $\mathrm{MK}_{2} \mathrm{~L}_{2}$ complex persists up to much higher temperatures than the $\mathrm{MK}_{2}$ and $M K_{2} \mathrm{~L}$ complexes. At the highest temperatures, the $\mathrm{MK}_{2} \mathrm{~L}_{2}$ state disappears. Only unfolded species (without $\mathrm{K}^{+}$) are formed, and TrisQ ligands are able to bind to these single strands (at least at high temperature).

MS-melting was repeated with three equivalents of TrisQ and gave similar results (Figure S 13), except that up to two TrisQ ligands can bind to the G-quadruplex at room temperature. With 22AG and 1 equivalent TrisQ (Figure S 14), the main difference is the absence of 2:1 ligand:quadruplex stoichiometry at all temperatures. A minor $\mathrm{ML}_{2}$ complex was observed only with the unfolded strand.

\section{A $24 \mathrm{TTG}+1$ eq PhenDC3}

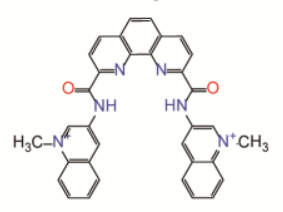

Phen-DC3

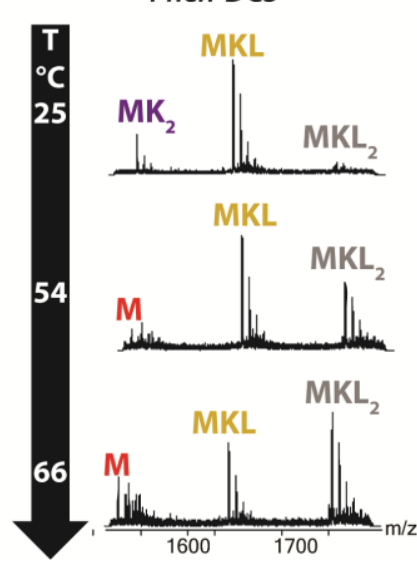

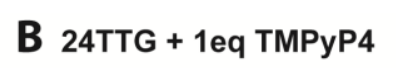
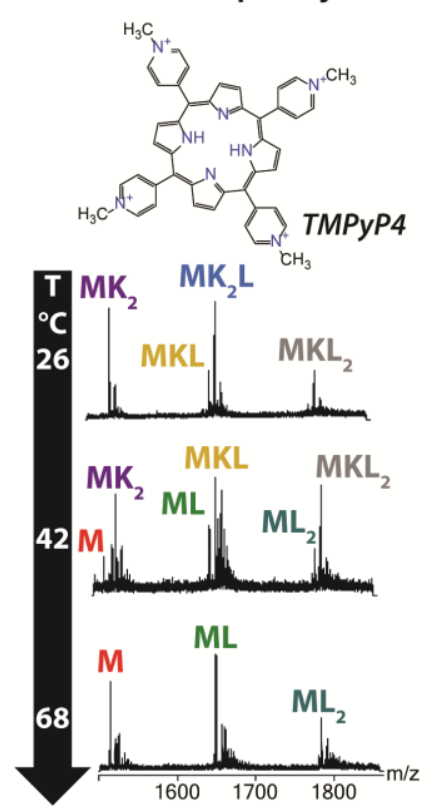

C 22GT + 1eq Cu-ttpy

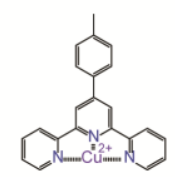

Cu(II)-ttpy

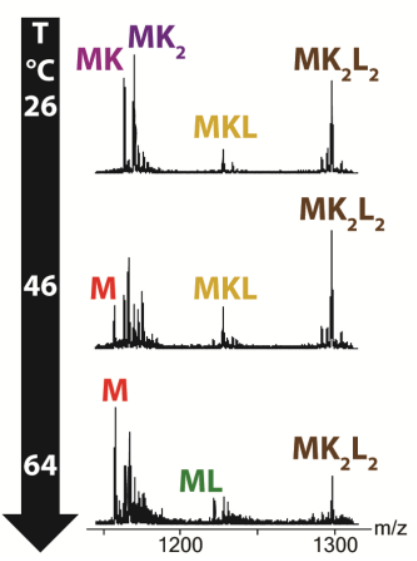

D 22GT + 3eq Pt-ttpy

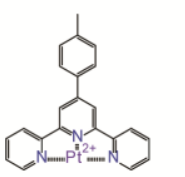

Pt(II)-ttpy

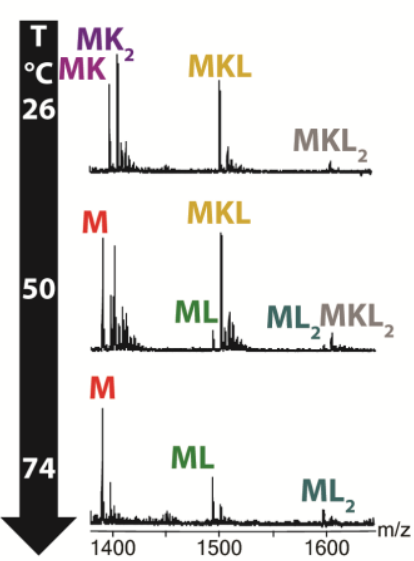

Figure 5. Mass spectra at different temperatures of $10 \mu \mathrm{M}$ of human telomeric DNA sequence (24TTG, $\mathrm{A}$ and $\mathrm{B} ; 22 \mathrm{GT}, \mathrm{C}$ and D) in the presence of one or three equivalent(s) A, Phen-DC3, B, TMPyP4, C, Cuttpy and D, Pt-ttpy.

Other ligands displayed different states upon thermal denaturation, as illustrated in Figure 5. At room temperature, Phen-DC3 binds to the 2-quartet antiparallel form of telomeric G-quadruplexes, predominantly with the MKL stoichiometry when there is one equivalent ligand. Similarly to TrisQ, a 2:1 (ligand:quadruplex) complex $\mathrm{MKL}_{2}$ forms above the melting temperature of the free G-quadruplex, for both 24TTG (Figure 5A and Figure S 15) and 22AG (Figure S 16). 
At room temperature, TMPyP4 binds to 24TTG with a similar profile as TrisQ does (Figure 5B and Figure S 17). However, the states appearing upon melting differ. Upon G-quadruplex melting (indicated by potassium release), the ligand binds to the unfolded form, so the apparent ligand:strand stoichiometries and abundances remain relatively constant. This highlights the poor selectivity of TMPyP4 for the Gquadruplex structures.

We also studied the thermal denaturation of $22 \mathrm{GT}$ in presence of two different metal complexes, $\mathrm{Cu}-$ tolyltertpyridine (Cu-ttpy) and Pt-tolyltertpyridine (Pt-ttpy) (Figure 5C-D and Figure S 18, Figure S 19 and Figure S 20). Cu-ttpy binds non-covalently and cooperatively to human telomeric G-quadruplexes, and the ligand-bound form is antiparallel with three quartets. ${ }^{39}$ At room temperature, the main complex is $\mathrm{MK}_{2} \mathrm{~L}_{2}$. MKL is also present, but minor. In contrast, Pt-ttpy binds covalently to adenines in the loops of telomeric sequences. ${ }^{53,54}$ With $22 \mathrm{GT}$, the main complex is MKL. Based on FRET-melting studies in potassium, ${ }^{53} \mathrm{Cu}$-ttpy had been discarded as a poor ligand, whereas Pt-ttpy retained attention owing to its higher $\Delta T_{\mathrm{m}}$. Yet, at $26^{\circ} \mathrm{C}$, the fraction of free G-quadruplex is identical with either 1 equivalent Cu-ttpy (Figure 5C and Figure S 18 and Figure S 19) or 3 equivalents Pt-ttpy (Figure 5D, Figure S 20). This illustrates a case where the ${ }^{\mathrm{FRET}} \Delta T_{\mathrm{m}}$ values are a poor indicator of ligand affinity, and led to an erroneous ranking. The reason lies in the very different states involved. For Cu-ttpy, the $\mathrm{MK}_{2} \mathrm{~L}_{2}$ species melts at a slightly higher temperature than the ligand-free G-quadruplex. Cu-ttpy also binds noncovalently to the unfolded form at high temperature. In contrast, because Pt-ttpy binds covalently, ${ }^{53,54}$ the complex can be considered a modified oligonucleotide, which unfolds (loses $\left.\mathrm{K}^{+}\right)$at a higher temperature $\left(56^{\circ} \mathrm{C}\right)$ than the unmodified $22 \mathrm{GT}\left(43^{\circ} \mathrm{C}\right)$.

\section{Thermodynamics of ligand binding to G-quadruplexes}

In the same way as for the G-quadruplexes alone, we quantified each stoichiometric state along the MSmelting experiments. The free ligand and free potassium ion concentrations were calculated by difference, from the mass balance equation. Knowing all concentrations gives access to the equilibrium binding constants and $\Delta G^{\circ}$ of each individual reaction $M+i K^{+}+j L \rightleftharpoons M K_{i} L_{j}$ at each temperature. When the reactant $\mathrm{M}$ and product $\mathrm{MK}_{i} \mathrm{~L}_{\mathrm{j}}$ were not observed simultaneously at a given temperature, the values were obtained from coupled equilibria. A Van't Hoff analysis then gives access to $\Delta H^{\circ}$ and $\Delta S^{\circ}$ of these reactions. The concentration plots and Van't Hoff plots are all shown in supporting information Figure S 11-Figure S 20. The values of the thermodynamic parameters are gathered in Table S 1. Figure 6 summarizes the key results for discussion, in the form of checkerboards of $\Delta \Delta G^{\circ}, \Delta \Delta H^{\circ}$ and $\Delta \Delta S^{\circ}$ values compared to the predominant G-quadruplex state without ligand ( $\mathrm{MK}_{2}$ for 24TTG, MK for 22AG). This 
allows one to visualize the cost or gain upon adding/removing each ligand (moving down/up on the checkerboard) or adding/removing each $\mathrm{K}^{+}$ion (moving right/left on the checkerboard) on the strand $\mathrm{M}$.

TrisQ binding to 24TTG is entropically favorable. With $-298 . \Delta \Delta S^{\circ}$ around $-20 \mathrm{kcal} / \mathrm{mol}$ per ligand bound, the system typically regains the entropy it had lost per potassium ion bound. In contrast, TMPyP4 binding to 24TTG is entropically indifferent, and favored only by enthalpy. This indicates a different binding mechanism.

The thermodynamic parsing according to stoichiometry harbors further information related to the conformational changes associated with ligand binding. In particular, MS allows one to isolate the states with only $1 \mathrm{~K}^{+}$ion bound, corresponding to 2 -quartet structures, and get individual thermodynamic parameters for that structure. For example, when one Phen-DC3 binds to $24 \mathrm{TTG}$, it ejects one $\mathrm{K}^{+}$. This binding, which is accompanied by a major topology rearrangement, is characterized by a favorable entropic contribution $\left(-298 . \Delta S^{\circ}{ }_{M K_{2} \rightarrow M K L}=-19 \mathrm{kcal} / \mathrm{mol}\right)$, in line with the liberation of one $\mathrm{K}^{+}$and one G-quartet. In contrast, the binding of one Phen-DC3 to 22AG has a totally different thermodynamic profile: it is enthalpically favored $\left(\Delta H^{\circ}{ }_{M K \rightarrow M K L}=-40 \mathrm{kcal} / \mathrm{mol}\right)$ and entropically unfavored $\left(-T \Delta S^{\circ}{ }_{M K \rightarrow M K L}=24 \mathrm{kcal} / \mathrm{mol}\right)$, suggesting either another binding mode to this G-quadruplex, or that the starting G-quadruplex has a very different conformation. This will be further discussed below.

\begin{tabular}{|c|c|c|c|c|c|c|c|c|c|c|}
\hline & \multicolumn{3}{|c|}{$\begin{array}{c}\Delta \mathbf{\Delta} \mathbf{G}^{\circ}(\mathbf{2 9 8 K}) \\
/ \mathrm{kcal}^{2} \mathrm{~mol}^{1}\end{array}$} & \multicolumn{3}{|c|}{$\begin{array}{c}\Delta \boldsymbol{\Delta} \mathbf{H}^{\circ} \\
/ \text { kcal.mol }^{1}\end{array}$} & \multicolumn{3}{|c|}{$\begin{array}{c}-298 . \Delta \Delta \mathbf{S}^{\circ} \\
/{\text { kcal. } \mathrm{mol}^{1}}^{1}\end{array}$} \\
\hline & & $O K$ & $1 \mathrm{~K}$ & $2 K$ & $O K$ & $1 K$ & $2 K$ & $O K$ & $1 \mathrm{~K}$ & $2 K$ \\
\hline \multirow{3}{*}{ 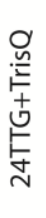 } & & $\begin{array}{l}11.5 \\
\pm 0.1\end{array}$ & & 0 & $\begin{array}{l}53 \\
\pm 3\end{array}$ & & 0 & $\begin{array}{l}-42 \\
\pm 3\end{array}$ & & 0 \\
\hline & $1 L$ & $\begin{array}{l}4.6 \\
\pm 0.1\end{array}$ & $\begin{array}{l}-2.7 \\
\pm 0.6\end{array}$ & $\begin{array}{l}-6.8 \\
\pm 1.7\end{array}$ & $\begin{array}{l}49 \\
\pm 4\end{array}$ & $\begin{array}{l}21 \\
\pm 6\end{array}$ & $\begin{array}{l}12 \\
\pm 3\end{array}$ & $\begin{array}{l}-45 \\
\pm 4\end{array}$ & $\begin{array}{l}-24 \\
\pm 4\end{array}$ & $\begin{array}{l}-19 \\
\pm 1\end{array}$ \\
\hline & $2 L$ & $\begin{array}{l}-3.2 \\
\pm 0.1\end{array}$ & $\begin{array}{l}-9.4 \\
\pm 0.1\end{array}$ & $\begin{array}{l}-13.5 \\
\pm 0.1\end{array}$ & $\begin{array}{l}41 \\
\pm 4\end{array}$ & $\begin{array}{l}32 \\
\pm 6\end{array}$ & $\begin{array}{l}21 \\
\pm 3\end{array}$ & $\begin{array}{l}-44 \\
\pm 4\end{array}$ & $\begin{array}{l}-41 \\
\pm 4\end{array}$ & $\begin{array}{l}-34.8 \\
\pm 1.6\end{array}$ \\
\hline \multirow{3}{*}{ 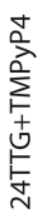 } & $O L$ & $\begin{array}{l}11.5 \\
\pm 0.1\end{array}$ & & 0 & $\begin{array}{l}53 \\
\pm 3\end{array}$ & & 0 & $\begin{array}{l}-42 \\
\pm 3\end{array}$ & & 0 \\
\hline & $1 L$ & $\begin{array}{l}3.9 \\
\pm 0.1\end{array}$ & $\begin{array}{l}-2.8 \\
\pm 0.1\end{array}$ & $\begin{array}{l}-7.5 \\
\pm 0.1\end{array}$ & $\begin{array}{l}52 \\
\pm 3\end{array}$ & $\begin{array}{l}0 \\
\pm 6\end{array}$ & $\begin{array}{l}-7 \\
\pm 1\end{array}$ & $\begin{array}{l}-48 \\
\pm 3\end{array}$ & $\begin{array}{l}-3 \\
\pm 5\end{array}$ & $\begin{array}{l}0 \\
\pm 1\end{array}$ \\
\hline & $2 L$ & $\begin{array}{l}-2.9 \\
\pm 0.1\end{array}$ & $\begin{array}{l}-10.2 \\
\pm 0.1\end{array}$ & & $\begin{array}{l}53 \\
\pm 4\end{array}$ & $\begin{array}{l}10 \\
\pm 7\end{array}$ & & $\begin{array}{l}-56 \\
\pm 3\end{array}$ & $\begin{array}{l}-20 \\
\pm 6\end{array}$ & \\
\hline \multirow{3}{*}{ 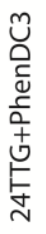 } & $O L$ & $\begin{array}{l}11.5 \\
\pm 0.1\end{array}$ & & 0 & $\begin{array}{l}53 \\
\pm 3\end{array}$ & & 0 & $\begin{array}{l}-42 \\
\pm 3\end{array}$ & & 0 \\
\hline & $1 L$ & & $\begin{array}{l}-5.0 \\
\pm 0.1\end{array}$ & & & $\begin{array}{l}14 \\
\pm 1\end{array}$ & & & $\begin{array}{l}-19 \\
\pm 1\end{array}$ & \\
\hline & $2 L$ & & $\begin{array}{l}-12.1 \\
\pm 0.1\end{array}$ & & & $\begin{array}{l}26.7 \\
\pm 1.7\end{array}$ & & & $\begin{array}{l}-38.9 \\
\pm 1.6\end{array}$ & \\
\hline \multirow{3}{*}{ 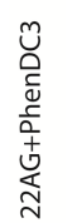 } & $O L$ & $\begin{array}{l}5.2 \\
\pm 0.6\end{array}$ & 0 & $\begin{array}{l}-4 \\
\pm 1.3\end{array}$ & $\begin{array}{l}28 \\
\pm 3\end{array}$ & 0 & $\begin{array}{l}-3 \\
\pm 6\end{array}$ & $\begin{array}{l}-22 \\
\pm 3\end{array}$ & 0 & $\begin{array}{l}-1 \\
\pm 5\end{array}$ \\
\hline & $1 L$ & & $\begin{array}{l}-16.3 \\
\pm 0.6\end{array}$ & & & $\begin{array}{l}-40 \\
\pm 5\end{array}$ & & & $\begin{array}{l}24 \\
\pm 4\end{array}$ & \\
\hline & $2 L$ & & $\begin{array}{l}-23.1 \\
\pm 0.6\end{array}$ & & & $\begin{array}{l}-49 \\
\pm 7\end{array}$ & & & $\begin{array}{l}25 \\
\pm 6\end{array}$ & \\
\hline
\end{tabular}

Figure 6. Thermodynamic parameters for potassium cation and ligand binding to G-quadruplexes. $\Delta \Delta \mathrm{G}^{\circ}$, $\Delta \Delta \mathrm{H}^{\circ}$ and $-298 . \Delta \Delta \mathrm{S}^{\circ}$ are relative to the folded G-quadruplex (MK2 for 24TTG, MK for 22AG, bold red zero). The values color-coded, indicating how favorable (green) or unfavorable (red) is a given state compared to the free G-quadruplex, should the reaction be carried out at $1 \mathrm{M}$ concentration of each partner. 
The reported uncertainties are the standard deviations from repeated experiments, considering uncertainty propagation when sequential reactions are used for the Van’t Hoff regressions.

\section{DISCUSSION}

\section{Uncertainties in the MS-melting method, and comparison with traditional UV-melting, CD-melting}

\section{or FRET-melting}

The contribution of random fluctuations to uncertainty was estimated from replicate experiments. For example, for $24 \mathrm{TTG}$ in $1 \mathrm{mM} \mathrm{KCl}$ (Table S 2), the standard deviation on the melting temperature is $1{ }^{\circ} \mathrm{C}$, which is similar to UV-melting or CD-melting. One significant source of uncertainty comes from a possible difference between the temperature of the emitter tip, protruding $0.5-1 \mathrm{~mm}$ from the copper bloc, and that of the copper block on which the temperature is monitored. We performed Comsol Multiphysics simulations with the block heated from 25 to $70{ }^{\circ} \mathrm{C}$ in room temperature $\left(25^{\circ} \mathrm{C}\right)$ air (Figure $\mathrm{S} 21$ ), and found that the temperature of the tip is lower than the temperature of the copper bloc by 0 to $-3{ }^{\circ} \mathrm{C}$.

The standard deviation on thermodynamic parameters from replicate experiments was $\sim 5-12 \%$ for $\Delta H^{\circ}$ and $\Delta S^{\circ}$, from the Van't Hoff plots. The uncertainty on $\Delta G_{298}{ }^{\circ}$ depends on how far the melting temperature is from $298 \mathrm{~K}$. To verify whether the $\Delta H^{\circ}$ and $\Delta S^{\circ}$ values obtained by MS-melting are reasonable, we also studied two well-characterized complexes: Hoechst $33258^{55}$ and Amsacrine ${ }^{56}$ (Scheme S 1) bound to the Dickerson-Drew dodecamer (dCGCGAATTCGCG) $)_{2}$. The difference in binding modes (groove binding versus intercalation, respectively) strongly affects the thermodynamic parameters. Chaires showed that the groove binding of Hoechst 33258 is entropically favored, ${ }^{57}$ and Graves reported that the binding of Amsacrine is enthalpically driven. ${ }^{56}$ Our results (supporting information Figure S 22 and Figure S 23) show that the values of $\Delta G^{\circ}$ agree, despite the slight differences in buffer. The values of $\Delta H^{\circ}$ and $\Delta S^{\circ}$ show more discrepancies, but are always of the same sign. We will thus base our discussion of MSmelting results on the sign and magnitude of the thermodynamic parameters rather than on the absolute values.

A significant source of uncertainty, compared to calorimetric methods, is the use of Van't Hoff plot, with the underlying assumption that the enthalpy is independent on the temperature. Calorimetry showed that this is usually not the case for G-quadruplexes. ${ }^{37,58}$ Not taking into account the heat capacity could give errors up to $20 \%{ }^{59}$ One possible solution is to perform several MS-melting experiments at different $\mathrm{K}^{+}$and/or ligand concentrations, so as to shift the melting temperature significantly, and thus obtain thermodynamic parameters at different temperatures. We explored this approach with T95-2T at $100 \mu \mathrm{M}$ 
and $1 \mathrm{mM} \mathrm{KCl}$ (Figure S 24). The difference in $\Delta H_{a s s n}{ }^{\circ}$ obtained around $45^{\circ} \mathrm{C}$ and $65^{\circ} \mathrm{C}$ is $13 \%$. The $\Delta C_{P, a s s n}{ }^{\circ}=-358$ cal K$^{-1}$ mol $^{-1}$ is in very good agreement with values obtained for other Gquadruplexes $^{58}$ (a phenomenon attributed to hydrophobic collapse ${ }^{60}$ ) so this approach will be worth exploiting in future experimental designs.

However, compared to all spectroscopic and calorimetric techniques, the significant advantage of MSmelting is the direct readout of the stoichiometry of each state. Consequently, the chemical equilibria for which one extracts the thermodynamic parameters are unambiguously defined. Importantly, multiple equilibria can be tracked simultaneously, whereas other techniques, including calorimetry, would struggle to disentangle the states or to interpret the chemical nature of the states extracted by singular value decomposition. ${ }^{35}$ Finally, defining baselines for each state is not difficult when treating MS-melting data, which is also a significant advantage compared spectroscopy-melting data. ${ }^{25,33}$

\section{The driving forces for potassium-induced G-quadruplex folding}

Using mass spectrometry, we distinguish G-quadruplex folded states via potassium binding, i.e. a multimolecular reaction:

$$
\begin{array}{ll}
M+i K^{+} \rightleftharpoons M K_{i} & \text { Equation 1 } \\
\Delta G^{\circ}{ }_{\text {assn }}=-R T * \ln \left(\frac{\left[M K_{i}\right]}{[M][K]^{i}}\right) & \text { Equation 2 }
\end{array}
$$

One should be cautious if the MS-melting results are compared with literature in which the folding is defined by a pseudo-unimolecular folding reaction:

$$
\begin{array}{ll}
U \rightleftharpoons F & \text { Equation 3 } \\
\Delta G^{\circ}{ }_{\text {fold }}=-R T * \ln \left(\frac{[F]}{[U]}\right) & \text { Equation 4 }
\end{array}
$$

is a conditional equilibrium binding constant (i.e., it depends on the experimental conditions, here most notably on the $\mathrm{KCl}$ concentration), and $\Delta G^{\circ}$ fold is related to $\Delta G^{\circ}$ assn by:

$$
\Delta G_{\text {fold }}^{\circ}=\Delta G^{\circ}{ }_{\text {assn }}-i R T * \ln \left[K^{+}\right] \quad \text { Equation } 5
$$

When discussing literature values one must be critical about how the stoichiometries were assigned. In MS, the stoichiometries are unambiguous and each stoichiometric state is quantified. With traditional methods, the determination of $i$ is more indirect (one may find non-integer numbers) and this is a possible source of discrepancy. Also, differences can come from other components of the solutions, most notably the ionic strength, which may influence the activity coefficients of DNA forms and of cations. Both in our work and in the G-quadruplex literature, the analytical concentrations are used as if they were equal to activities. Finally, the state partitioning in MS is defined by the stoichiometry, whereas spectroscopic 
techniques (NMR) or data treatment techniques (SVD) may partition the ensemble into very different groups. For example, while the specific MK stoichiometry is a unique signature for a 2-quartet state (only antiparallel structures are known to date), the $\mathrm{MK}_{2}$ complex can be either parallel, antiparallel or hybrid 3-quartet, or the two-quartet structure with one extra cation coordinated between a quartet and a triplet.

However, the thermodynamics of $\mathrm{MK}_{2}$ formation will differ depending on its structure. Figure 7 shows the thermodynamic parameters per specific cation bound for four telomeric sequence variants. For 24TTG, no specific MK complex is detected, and the energy per cation is calculated as half the energy of specific binding of the two cations. We verified by ${ }^{1} \mathrm{H}$ NMR that, in our $1-\mathrm{mM} \mathrm{KCl}$ conditions, $24 \mathrm{TTG}$ forms a hybrid-1 structure and 22GT forms an antiparallel 2-quartet structure, like in $100 \mathrm{mM} \mathrm{KCl}$ (supporting information Figure S 25). 23TAG and 22AG show both the MK and the $\mathrm{MK}_{2}$ stoichiometry. However, the thermodynamics of cation binding are very different.

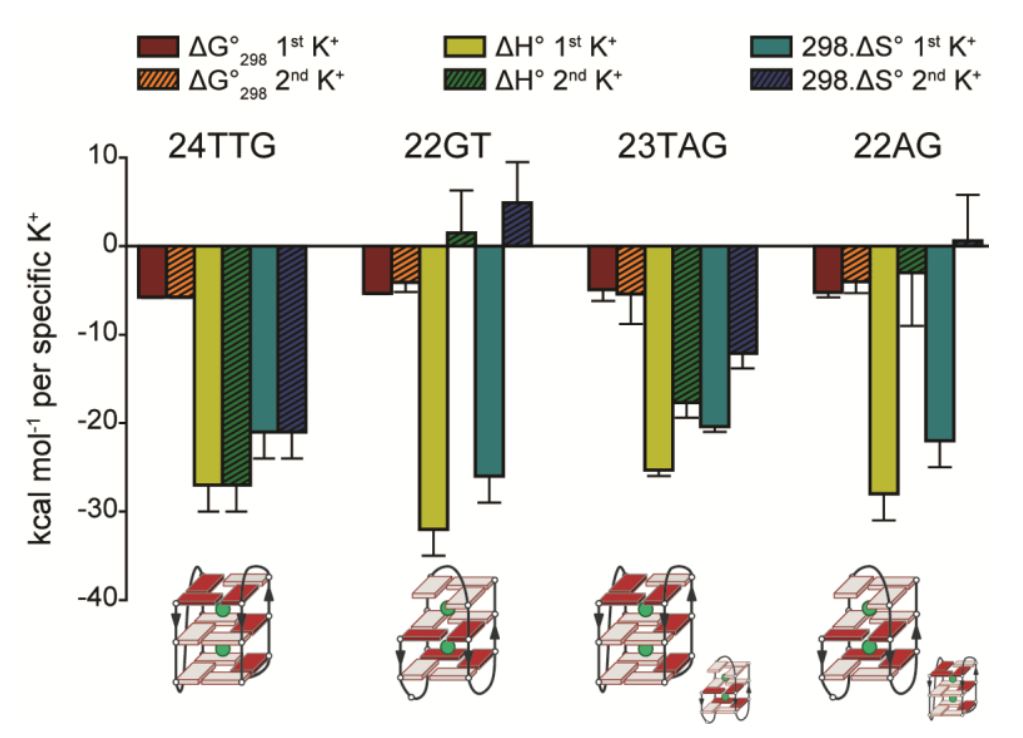

Figure 7. $\Delta G^{\circ}, \Delta H^{\circ}$ and $T \Delta S^{\circ}$ per cation for four different telomeric sequence variants. Bottom: structure of the $\mathrm{MK}_{2}$ complex, based on NMR for 24TTG and 22GT, and deduced predominant, based on thermodynamic signature, for 23TAG and 22AG.

The similar thermodynamic profiles of potassium binding to $22 \mathrm{AG}$ and $22 \mathrm{GT}$ suggest that the Gquadruplexes formed by $22 \mathrm{AG}$ and $22 \mathrm{GT}$ are very similar. For 22GT, which folds into an antiparallel 2quartet with a triplet of guanines at up to $100 \mathrm{mM} \mathrm{K}^{+},{ }^{17}$ the first $\mathrm{K}^{+}$is expected to bind between the two quartets, and the second $\mathrm{K}^{+}$could bind in-between one quartet and the triplet of guanines, without altering the MK structure. Our results suggest that $22 \mathrm{AG}$ also forms a similarly complex ensemble of structures in the $\mathrm{mM} \mathrm{K}^{+}$concentration range; the ${ }^{1} \mathrm{H}$ NMR spectrum shows multiple coexisting species (Figure $\mathrm{S}$ 25). When compared to the fractions predicted by Boncina et al. for states U, I and F, the 2-quartet structure would correspond to the intermediate I. It is likely that, at higher $\mathrm{K}^{+}$concentration, the fraction 
of truly 3-quartet structures increases. The comparison between 23TAG and 22AG shows that a single thymine on the 5'-end suffices to drive the equilibrium significantly towards the hybrid-1 structure. The potassium binding thermodynamics for the $\mathrm{MK}_{2}$ complex of 23TAG is much more similar to that of 24TTG, and the major peaks in the ${ }^{1} \mathrm{H}$ NMR spectrum of $23 \mathrm{TAG}$ at $1 \mathrm{mM} \mathrm{KCl}$ are identical to those found in $100 \mathrm{mM} \mathrm{KCl}$, where a hybrid-1 structure was solved. A second minor set of imino proton peaks, indicating the presence of at least one other structure, is also visible. Upon heating, this set of peaks persists at higher temperature than the hybrid-1 structure (Figure S 26), and could thus correspond to the MK complex.

The main difference between the different potassium binding modes is that the formation of each quartet- $\mathrm{K}^{+}$-quartet units is strongly enthalpically favored and entropically unfavored, whereas the formation of a extra quartet- $\mathrm{K}^{+}$-triplet unit is entropically favored. This means that the driving force for proper G-quadruplex folding (G-quartets only) comes from bond formation, and that this requires significantly stiffening the conformation. However, the cation-mediated stacking of a triplet is entropically favorable despite the additional conformational restrictions, and the main contribution may thus be water release.

Also, a positive $T \Delta S^{\circ}$ contribution for triplet formation means that triplet formation is favored when the temperature is increased. This is why the population of the "misfolded" (two quartets instead of three) structures can increase with temperature, as observed for the MK state in 23TAG (Figure 3F) or for the intermediate state (I) defined by Boncina et al. Finally, the positive $T \Delta S^{\circ}$ for potassium-stabilized triplet formation gives some credit to the hypothesis of "G-triplex" formation at intermediate temperatures upon thermal denaturation. ${ }^{61,62}$ Although we do not observe here pure G-triplexes, our results suggest that potassium-stabilized guanine triplets may indeed be favored at higher temperatures than pure quartets, for entropic reasons.

Definition of the melting temperature $\left(T_{m}\right)$, and pitfalls in using spectroscopy-based $\Delta T_{m}$ values to

\section{rank ligand binding affinities}

The $T_{\mathrm{m}}$ is the temperature at which half of the population is unfolded. In MS-melting of G-quadruplexes, the $T_{\mathrm{m}}$ can be inferred from the concentration of all potassium-free forms (with and without ligand). In MS-melting of intermolecular complexes (e.g., duplexes), the unfolded state corresponds to the single strands. In spectroscopic techniques, the $T_{\mathrm{m}}$ is often estimated from the median between the hightemperature and low-temperature baselines. ${ }^{33}$ However, when many ensembles are populated as a function of temperature, which often happens in presence of ligands, this simplistic approach fails because 
the transitions are no longer sigmoidal (the temperature of half-drop of signal must be used instead, and the annotation $T_{1 / 2}$ is then preferred). For example, for the binding of TrisQ to 24TTG in Figure 4, up to eight ensembles are populated. In addition, some ensembles increase, then decrease over the melting experiment. MS-melting offers an unbiased way to determine melting temperatures, because the signal of each folded and unfolded state is quantified simultaneously.

In the G-quadruplex research community, ligand screening often starts with a ranking according to a melting assay. A common way to rank ligand binding affinities is to calculate the $\Delta T_{\mathrm{m}}$ or $\Delta T_{1 / 2}$ from experiments with and without ligand. Disentangling the states by native MS reveals the potential pitfalls when screening ligands using $\Delta T_{\mathrm{m}}$ values. For identical $\Delta G^{\circ}{ }_{298}$ values, entropically favored ligand binding modes give higher $\Delta T_{\mathrm{m}}$ values than enthalpically favored ligand binding modes. This is illustrated by simulation. For the simple case of ligand binding to the $\mathrm{MK}_{2}$ complex of $24 \mathrm{TTG}$ without affecting the topology, Figure 8 shows the simulated melting temperatures of $10 \mu \mathrm{M} 24 \mathrm{TTG}$ in presence of $1 \mathrm{mM} \mathrm{KCl}$, without ligand (Fig. 8A), and in presence of $10 \mu \mathrm{M}$ of three hypothetical ligands, having the same binding free energy at $298 \mathrm{~K}\left(\mathrm{~K}_{\mathrm{D}}=1.35 \mu \mathrm{M}\right)$ but different enthalpy/entropy contributions. In Figure 8B, the ligand binding is enthalpically driven and entropically unfavorable; in Figure $8 \mathrm{C}$, the ligand binding is slightly enthapically favorable and entropically neutral; in Figure 8D the ligand binding is purely entropy-driven. The latter gives the highest $\Delta T_{\mathrm{m}}\left(12.5^{\circ} \mathrm{C}\right)$, whereas the enthalpically favorable ligand gives only a marginal $\Delta T_{\mathrm{m}}\left(1^{\circ} \mathrm{C}\right)$.

Thus, when ligands having different binding modes are compared within a series, the $\Delta T_{\mathrm{m}}$ ranking is not a good predictor of affinity ranking at other temperatures. MS-melting experiments allow to estimate the equilibrium binding constants (affinities) at each temperature, and are thus key to lift discrepancies between melting experiments and isothermal $K_{\mathrm{D}}$ determinations. Furthermore, $\Delta T_{\mathrm{m}}$ ranking may have led to favoring ligands having an entropically-favored binding mode compared to ligands with enthalpicallydriven binding. The prevalence of melting assays as first screen may have contributed to lower the diversity of ligand binding modes discovered until now.
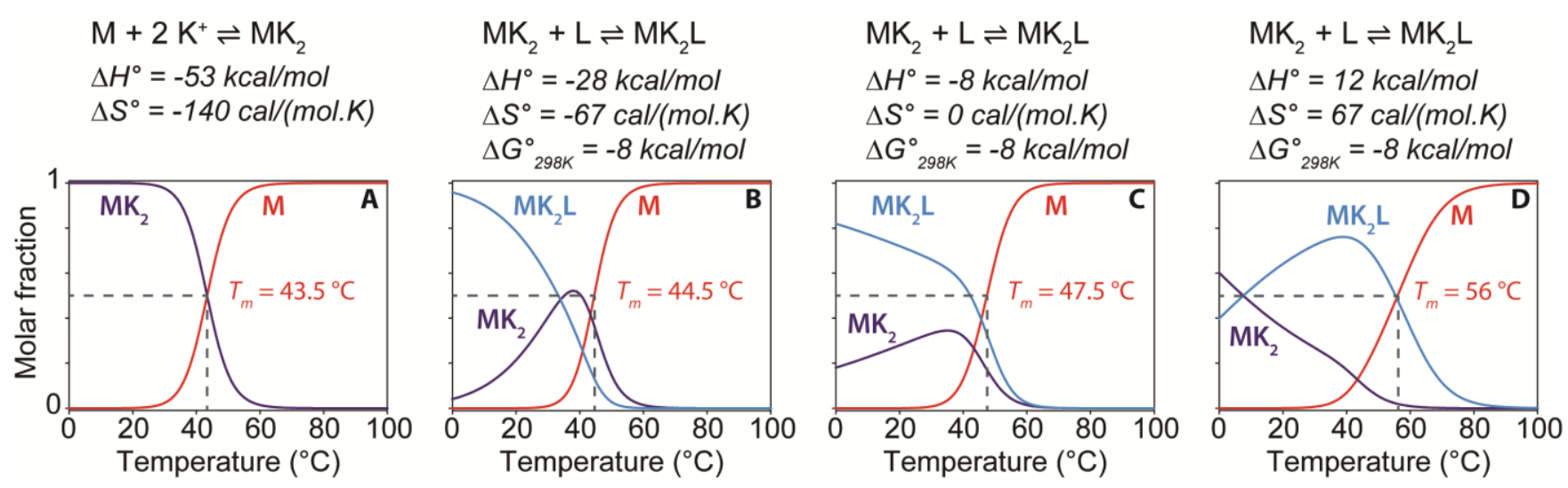
Figure 8: Simulated melting curves of $10 \mu \mathrm{M}$ 24TTG in $1 \mathrm{mM} \mathrm{K}^{+}$(thermodynamic parameters obtained experimentally in $100 \mathrm{mM}$ TMAA), alone (A) and in presence of $10 \mu \mathrm{M}$ ligand (B-D). The three ligands have the same binding affinity $\left(\Delta \mathrm{G}^{\circ}\right)$ at $298 \mathrm{~K}$, but different binding enthalpies and entropies. The ligand with entropy-driven binding shows the highest melting temperature, defined as the temperature at which half of the G-quadruplex is denatured (molar fraction of $M=0.5$ ).

\section{Thermodynamic signatures of ligand binding, including ligand-induced conformational changes}

Planar aromatic ligands such as TrisQ are expected to stack on external G-quartets. ${ }^{63,64} \mathrm{We}$ found that the binding of TrisQ to 24TTG is enthalpically unfavorable. This is compatible with stacking because in the ligand-free form, external G-quartets are often capped by additional base pairs. ${ }^{19}$ Ligand end-stacking disrupts these interactions, resulting in unfavorable enthalpic and favorable entropic contributions. The release of solvation ions/molecules from the ligand and the G-quadruplex can also contribute to the entropy gain.

In line with previous reports based on calorimetry, ${ }^{65,66}$ we found that the binding of Phen-DC3 to $22 \mathrm{AG}$ is enthalpically driven. The previous studies suggested that the displacement of water molecules from the binding interface is responsible for the high affinity. However, we found that the thermodynamic signature for the binding of Phen-DC3 to 24TTG is very different compared to 22AG, so the hypothesis of water release as a driving force does not hold. Our interpretation is that the thermodynamic signatures reflect that the starting structures are different. From potassium binding thermodynamics, we concluded above that 22AG folds mainly into 22GT-like structures (2-quartets 1-triplet of guanines antiparallel Gquadruplex) in our experimental conditions, so there is no major topology rearrangement upon binding of Phen-DC3 to 22AG. We propose that the enthalpically favorable and entropically unfavorable character of Phen-DC3 binding to the 2-quartet structure is due to the formation of new hydrogen bonds between the ligand and the guanines which are left free on both ends of the 2-quartet core. In contrast, upon binding of Phen-DC3, 24TTG therefore has to completely rearrange its topology, and this contribution translates into major differences in the ligand binding thermodynamics.

For TMPyP4, Lah et al. described that the binding of TMPyP4 to $22 \mathrm{AG}$ is mainly driven by entropy. ${ }^{66}$ Despite the fact the CD signals in presence of the ligand decreased significantly, the authors assumed that no particular conformational changes were occurring upon binding of TMPyP4, and interpreted the entropically-driven binding as due to solvent release from the buried hydrophobic surfaces. Our MSmelting results provide a much more complete picture. With the sequence $24 \mathrm{TTG}$, we could separately characterize TMPyP4 binding to the 3-quartet hybrid structure, to the 2-quartet structure, and to the 
unfolded form. The binding to the hybrid-1 structure is enthalpically favored, the binding of to the 2quartet structure is slightly entropically favored, and the binding to the unfolded structure is very entropically favored. The binding mode of TMPyP4 to G-quadruplexes has remained controversial: some reports show that it binds and stabilizes G-quadruplexes, ${ }^{67}$ others show that TMPyP4 changes the Gquadruplex structure, ${ }^{68}$ and others show that it unfolds G-quadruplexes. ${ }^{69-71}$ Here we show that all types of binding coexist, and that the distribution of final states depends on the ligand concentration ratio and on the temperature.

\section{CONCLUSIONS}

By analyzing G-quadruplexes formed in the presence of potassium and their complexes with ligands using a temperature-controlled electrospray source, we could, in a single melting experiment, determine the enthalpy, entropy and free energy of formation of each complex based on its stoichiometry. This allowed us to study the thermodynamics of G-quadruplex folding, one potassium ion at a time. Potassium binding between a G-quartet and a triplet has a very different thermodynamic profile than the formation of a quartet- $\mathrm{K}^{+}$-quartet unit, because it is entropically favored. The cause may be that the entropy of water release upon $\mathrm{K}^{+}$binding is larger than the conformational entropy loss due to the triplet formation. An important consequence is that slipped structures may become favorable as the temperature is increased, below the melting temperature at which the entire G-quadruplex unravels.

In several cases, the mass spectra revealed states that were not suspected based on traditional melting assays, and MS-melting experiments are particularly useful to explain apparent inconsistencies between isothermal and melting assays. The ability to distinguish between unfolded structures (no $\mathrm{K}^{+}$bound), 2quartet structures $\left(1 \mathrm{~K}^{+}\right.$bound $)$and 3-quartet structures $\left(2 \mathrm{~K}^{+}\right.$bound $)$is important, because several popular ligands (360A, Phen-DC3) are capable of inducing major changes of topology towards 2-quartet folds in telomeric sequences. We also observed such complexes with the ligands TrisQ, TMPyP4 and Cu-ttpy.

In the melting of ligand complexes, we also found that, upon unfolding of the main 1:1 (ligand:quadruplex) complex, 2:1 complexes are formed alongside unfolded forms. This comes from a change of stoichiometric ratio between ligand and (remaining) quadruplex as the ligand-free fraction unfolds. Thus, even when a melting experiment is carried out with one equivalent of ligand, the melting of the higher stoichiometries may ultimately determine the magnitude of the $\Delta T_{\mathrm{m}}$.

We also found that when the ligand binding stoichiometries differ from ligand to ligand, or when ligand binding is associated with topology changes, the $\Delta T_{\mathrm{m}}$ values do not reflect the ligand binding constants. The full thermodynamic profiles for ligand binding thus bring important insight into the driving forces 
for ligand binding. The present study highlighted how the thermodynamics contributions depended on the binding scenarios. For example, ligand end-stacking (TrisQ on 24TTG), releasing both water bound to the ligand and conformational strain in end-stacked bases, is favored entropically, whereas ligand hydrogen bonding (hypothesized for Phen-DC3 on 22AG) translates into more favorable enthalpic contributions. Major topology changes upon ligand binding also translates into specific thermodynamic signatures, which are particularly useful given that no high-resolution structure of ligands inducing changes of topology is currently available.

In the future, the most powerful thermodynamic characterization of nucleic acid/drug melting will come from a combination of techniques. The quantitative parsing among different states based on their stoichiometry is the key advantage of mass spectrometry. The results illustrate the richness of information obtained from MS-melting experiments alone. Combining MS-melting with CD-melting can further parse the states (especially the $\mathrm{MK}_{2}$ complexes) according to stacking topology, and differential scanning calorimetry experiments in the same experimental conditions would provide key information on the contribution of solvation effects thanks to $\Delta C^{\circ}$ p values. Full thermodynamic characterization by such combination of techniques including MS would bring key insight into the driving forces for G-quadruplex cation-induced folding and ligand binding. 


\section{MATERIALS AND METHODS}

\section{Oligonucleotides and ligands}

Oligonucleotides were purchased lyophilized and RP-cartridge purified from Eurogentec (Seraing, Belgium). Stock solutions were prepared at 0.80 or $1.00 \mathrm{mM}$ concentration in nuclease-free water (Ambion, Fisher Scientific, Illkirch, France). The concentrations were determined using the Beer-Lambert law by measuring the absorbance at $260 \mathrm{~nm}$. The extinction coefficients were obtained from the IDT website using the Cavaluzzi-Borer correction. ${ }^{72}$ The solutions were then diluted to $200 \mu \mathrm{M}$ before being prepared into the folding conditions. Trimethylammonium acetate (TMAA, Ultra for UPLC) ammonium

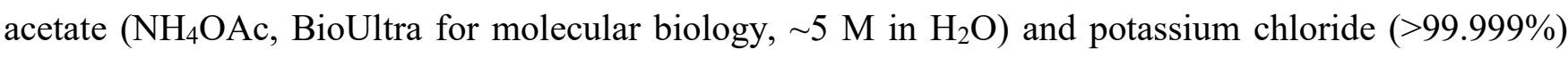
were purchased from Sigma-Aldrich (Saint-Quentin Fallavier, France). The $\mathrm{pH}$ of the sprayed solutions was 6.8 .

The ligands TrisQ and Phen-DC3 were synthesized as described elsewhere ${ }^{52,73}$ and provided by Prof. Teulade-Fichou from Institut Curie, Paris. TrisQ and Phen-DC3 were solubilized at $2 \mathrm{mM}$ in DMSO before being diluted to $500 \mu \mathrm{M}$ using water. TMPyP4 was purchased from Sigma-Aldrich. The concentration of these three ligands was determined using UV absorbance. The following extinction coefficients and wavelengths were used: for Phen-DC3: $\varepsilon_{320}=62400 \mathrm{~cm}^{-1} \mathrm{M}^{-1}$, for TrisQ $\varepsilon_{257}=70900$ $\mathrm{cm}^{-1} \mathrm{M}^{-1}$ and for TMPyP4 $\varepsilon_{424}=226000 \mathrm{~cm}^{-1} \mathrm{M}^{-1}$. Cu-ttpy and Pt-ttpy were synthesized in house using previously established protocols..$^{39,53}$ Their concentrations were determined from careful weighing. Amsacrine hydrochloride was obtained from Sigma and the bisbenzimide Hoechst 33258 from SigmaAldrich (Saint-Quentin Fallavier, France). Table 1 lists the G-quadruplex forming sequences used in this article. Moreover, we used the control sequences 21nonG4 (d(GGGATGCGACGAGAGGACGGG)), 22nonG4 (d(GGGATGCGACAGAGAGGACGGG)) and the self-complementary duplex-forming sequences DK33 (d(CGTAAATTTACG), DK66 (d(CGCGAATTCGCG)) and DK100 (d(CGCGGGCCCGCG)) for control experiments including the tests with minor groove binders and intercalators.

\section{Native mass spectrometry}

Melting experiments were performed on an Agilent 6560 IMS-Q-TOF (Agilent Technologies, Santa Clara, CA, USA), using a home built source described in the next section. The experiments were performed in negative mode. The instrument allows recording the drift time distribution of each $\mathrm{m} / \mathrm{z}$ species, which helps to discern eventual conformational ensembles. One MS spectrum is summed every $\sim 1 \mathrm{~s}$. The borosilicate nanospray emitters were purchased from ThermoFisher (ref. ES388) and opened manually. The capillary voltage was set between 1.0 and $1.5 \mathrm{kV}$. The spray capillary is grounded and the 
source entrance voltage is set to high voltage. A backpressure of 0.1 to 1 bar was applied to ensure a continuous production of ions during the entire melting experiment. The gas in the ion mobility cell of the instrument was helium (Alphagaz 2 grade from Air Liquide, $\mathrm{H}_{2} \mathrm{O}<3 \mathrm{ppm}, \mathrm{C}_{\mathrm{n}} \mathrm{H}_{\mathrm{m}}<0.5 \mathrm{ppm}, \mathrm{O}_{2}<2$ ppm). The pumping system in the source region was modified using a second Triscroll TS800 pump (Agilent Technologies). ${ }^{74}$ Some experiments (sequence T95-2T) were reproduced on a Synapt G2S (Waters, Manchester, UK), using similar conditions. In this instrument, the cone is grounded and the source is connected to the high voltage.

\section{Home-built temperature-controlled nanoelectrospray source, TCnESI}

The TCnESI source is a classical nESI source in which the entire emitter is embedded in a copper block (Typically, 0.5-1 mm of the emitter protrudes outside of the block) (Figure S 1). The copper piece was made by the ETH workshop. This block is heated or cooled by a Peltier element purchased from RSonline (Adaptive ET-127-10-13-RS, 15.7 V, 37,9 W). Its power is supplied by a Kikusui PMX18-5A power supply (Kikusui Electonics Corp., Japan) which is remote-controlled by a LabView software (National Instruments). The temperature of the copper block was measured using a bolt mount thermistor sensor (5000 Ohms, ON-950-44005, Omega, standard accuracy of $0.2{ }^{\circ} \mathrm{C}$ from 0 to $70{ }^{\circ} \mathrm{C}$ ) plugged into a Keithley 2701E multimeter (Equipements Scientifiques, Garchies, France), itself connected to the LabView software. The LabView code is home-made and consists in a loop adjusting the temperature.

For the melting experiments, a ramp was programmed to scan from 25 to 85 or $95{ }^{\circ} \mathrm{C}$ at $2{ }^{\circ} \mathrm{C} / \mathrm{min}$. This rather fast ramp maximized the chances of recording the entire melting in a single experiment without losing the spray signal. Typically, a single nanospray emitter, in our conditions, lasts for 30 to 60 minutes. Note that similar ramp speeds are customary in FRET-melting experiments, wherein the small sample wells respond quickly to temperature changes. ${ }^{35,75}$ To check whether this scan speed could affect the results or not, we performed the melting of the same complex (the DK66 duplex in $100 \mathrm{mM} \mathrm{NH}_{4} \mathrm{OAc}$ ) using 2 and $1 \mathrm{C}^{\circ} / \mathrm{min}$ and found very similar results $\left(\mathrm{T}_{\mathrm{m}}=53.6\right.$ and $53.9{ }^{\circ} \mathrm{C}$, supplementary Figure $\left.\mathrm{S} 27\right)$. As an additional control, in supplementary Figure S 28, we show the thermal denaturation of three autocomplementary DNA duplexes containing increasing number of $\mathrm{G} \equiv \mathrm{C}$ base pairs $(\mathrm{DK} 33,33 \% \mathrm{G} \equiv \mathrm{C}$, DK66, 66\% $\mathrm{G} \equiv \mathrm{C}$ and $\mathrm{DK} 100,100 \% \mathrm{G} \equiv \mathrm{C})$ monitored using mass spectrometry. At low temperature, the duplexes $\left(\mathrm{M}_{2}\right)$ are formed in $100 \mathrm{mM} \mathrm{NH} 4 \mathrm{OAc}$. When the temperature is increased, the duplexes dissociate into monomers. At high temperature, only the single strand can be observed. The quantification reveals the evolution of the two species as a function of temperature. The curves were fitted using sigmoid functions and the melting temperature (as defined by the inflexion point) determined. As expected due to the increasing number of hydrogen bounds between the two strands, the melting temperature is shifted 
towards higher temperatures with increasing number of $\mathrm{G} \equiv \mathrm{C}$ base pairs $\left(\mathrm{T}_{\mathrm{m}}(\mathrm{DK} 33)=43.5{ }^{\circ} \mathrm{C}<\right.$ $\left.\mathrm{T}_{\mathrm{m}}(\mathrm{DK} 66)=53.6^{\circ} \mathrm{C}<\mathrm{T}_{\mathrm{m}}(\mathrm{DK} 100)=64.6^{\circ} \mathrm{C}\right)$.

\section{Circular dichroism}

A Jasco J-815 spectrophotometer was used to perform the CD experiments. A quartz cell of $2 \mathrm{~mm}$ path length and $10 \mathrm{~mm}$ width was used. The temperature ramp was set to $0.4{ }^{\circ} \mathrm{C} / \mathrm{min}$ from 4 to $90{ }^{\circ} \mathrm{C}$. The temperature ramp is halted during the acquisition of each spectrum, which consists of two scans acquired at $100 \mathrm{~nm} / \mathrm{min}$. A linear baseline was subtracted from each spectrum using the mean value between 320 and $350 \mathrm{~nm}$. CD data were converted to molar circular-dichroic absorption $(\Delta \varepsilon)$ based on DNA total concentration $(C)$ using the following equation,

$$
\Delta \varepsilon=\theta /(32980 \times C \times l) \quad \text { Equation } 6
$$

where $\theta$ is the ellipticity in mdeg and $l$ the length of the cell in $\mathrm{cm}(0.2 \mathrm{~cm})$.

\section{Mass spectrometry data processing}

For the duplexes, the peaks corresponding to the monomer and to the dimer were integrated as a function of temperature. The charge states were summed and normalized to the total concentration. If the peaks overlap in mass (for example a monomer $\mathrm{M}^{3-}$ and a dimer $\mathrm{M}_{2}{ }^{6-}$ ), ion mobility is used to separate the peaks (supplementary Figure S 29). We considered all response factors equal. The difference between the duplex melting temperatures obtained by MS and by other methods could come in part from this assumption.

For the G-quadruplexes, the unfolding was monitored by a change in the number of bound $\mathrm{K}^{+}$. We found that, upon temperature increase, the shift in charge state is very small and not due to the thermal denaturation of the complexes because similar shifts are observed for non-G-quadruplex forming sequences (Figure S 30 and Figure S 31).

The peaks corresponding to the different $\mathrm{K}^{+}$and $\mathrm{L}$ stoichiometries were integrated as a function of temperature. From the relative abundances, the DNA concentrations are obtained and the free $\mathrm{K}^{+}$or ligand concentrations can be obtained by difference. For each temperature, the sum of the different species was normalized to the total concentration $(10 \mu \mathrm{M})$, using the following equation:

$$
\sum_{n} \sum_{i} \sum_{j} I_{M_{n} K_{i} L_{j}}=10 \mu M \quad \text { Equation } 7
$$

where $I$ is the integral of the corresponding peaks obtained from the MS experiment, $M, K^{+}$and $L$ are the DNA, potassium cations and ligands, respectively, and $n$, i and $j$ their stoichiometries. For $\mathrm{K}^{+}$binding to the G-quadruplexes, and for ligand binding to either duplexes or G-quadruplexes, the assumption that response factors are equal is supported by previous studies. ${ }^{39,41,76}$

When a solution containing $100 \mathrm{mM}$ TMAA and $1 \mathrm{mM} \mathrm{KCl}$ is sprayed, non-specifically bound $\mathrm{K}^{+}$ cations are visible on the peaks of the DNA, whether it is folded or not. To distinguish specific from 
nonspecific adducts, we used a method described previously. ${ }^{38,41,77}$ Briefly, the distribution of adducts on a reference is used to reconstruct the specific distribution. We checked using the 21 and 22 nonG4 sequences (which bind $\mathrm{K}^{+}$only non-specifically) that the distribution of nonspecific adducts is not affected by the temperature (Figure S 30). For each sequence, we used the distribution of adducts obtained at high temperature $\left(80-85^{\circ} \mathrm{C}\right)$ to quantify the contribution of nonspecific adducts to the ion signal, considering that in this temperature range all DNA structures are unfolded. Two nonspecific adducts were taken into account for the 5-charge state and one for the 6- charge state. The detailed mathematical procedure is reported in the supplementary material (Figure S 32).

In Figure S 33, the dotted lines highlight the differences in the melting temperatures obtained for the treatment of each charge state. These differences were negligible (Table S 2). All quantitative results shown in the manuscript are the average of the two charge states. Note that the 4- charge state is also observed but was not included in the summation because the 4- ions present a very high number of nonspecific adducts and would thus bring more uncertainty. ${ }^{41}$

The equilibrium constants are calculated from the ratios of the concentrations, assuming they are equal to the ratios of their activities. The general form of the reactions for which the thermodynamic parameters were extracted (including for duplexes) is given by:

$$
n M+i K^{+}+j L \rightleftharpoons M_{n} K_{i} L_{j} \quad \text { Equation } 8
$$

The stoichiometric coefficients $n, i$ and $j$ are not adjustable parameters, but are integer numbers determined unambiguously from the mass spectrometric measurements. The equilibrium constant of the association reactions are thus:

$$
K_{a}=\frac{\left[M_{n} K_{i} L_{j}\right]}{[M]^{n}\left[K^{+}\right]^{i}[L]^{j}} \quad \text { Equation } 9
$$

The $\Delta G_{a s s n}^{\circ}$ was determined using:

$$
\Delta G_{a s s n}^{\circ}=-R T \ln K_{a}=\Delta H_{a s s n}^{\circ}-T \Delta S_{a s s n}^{\circ} \quad \text { Equation } 10
$$

where $R$ is the molar gas constant and $T$ is the temperature in K. We used the Van't Hoff plot (ln $K_{a}$ vs. $1 / \mathrm{T})$ to determine the enthalpic and entropic contributions to the association reaction. The temperature ranges used for the Van't Hoff plots are reported in the figures of the supplementary material.

$$
\ln K_{a}=-\frac{\Delta H_{a s s n}^{\circ}}{R} \times \frac{1}{T}+\frac{\Delta S_{a s s n}^{\circ}}{R} \quad \text { Equation } 11
$$

When $\Delta G_{a s s n}^{\circ}$ could not be obtained directly at $298 \mathrm{~K}$ from the measurement, $\Delta G_{a s s n}^{\circ}$ was obtained by extrapolation, using Equation 10 and the uncertainties were calculated from the sum of the uncertainties on $\Delta H_{a s s n}^{\circ}$ and $T \Delta S_{a s s n}^{\circ}$. 
In most cases the Van't Hoff plots were linear, and in such cases the $\Delta H_{\text {assn }}^{\circ}$ determined from the slope in the temperature range wherein $K_{a}$ could be determined confidently (nonzero concentration of each component) can be relatively safely extrapolated to other temperatures. In some cases, however, the plots are not perfectly linear, meaning that $\Delta H_{\text {assn }}^{\circ}$ changes with temperature and that $\Delta C_{p}^{\circ}$ is $\neq 0 .{ }^{58}$ In general, the errors on the linear fits are larger for these cases. Unfortunately, signal flucturations precluded any reliable fitting using quadratic functions.

In cases where the equilibrium constant of a reaction $M \rightarrow M_{n} K_{i} L_{j}$ cannot be measured at any temperature because neither species is sufficiently abundant, it is still possible to determine the equilibrium constant and thermodynamic parameters for other coupled equilibria (for example $M \rightarrow$ $M_{m} K_{k} L_{l}$ and $\left.M_{m} K_{k} L_{l} \rightarrow M_{n} K_{i} L_{j}\right)$, and then obtain the thermodynamic parameters by difference. The total uncertainty is obtained by standard propagation of individual uncertainties, assuming they are uncorrelated.

\section{Acknowledgements}

The authors thank Marie Paule Teulade-Fichou for providing Phen-DC3 and TrisQ, Anirban Ghosh for the NMR spectra, Martin Czar for help in the Matlab simulation of Figure 8, and Jérôme F. Käslin for help with the cover art. The research leading to these results has received funding from the European Research Council under the European Union's Seventh Framework Programme (FP7/2007-2013) / ERC2013-CoG 616551-DNAFOLDIMS and FP7-PEOPLE-2012-CIG-333611-BIOPHYMS, from the Inserm [ATIP-Avenir Grant no. R12086GS], from the Conseil Régional Aquitaine [Grant no. 20121304005] and supported by the ETH [Grant no. 200020-178765].

\section{SUPPLEMENTARY}

Supplementary MS, CD, NMR spectra and melting data as described in the text is available free of charge via the Internet at http://pubs.acs.org.

The data used in used in this publication will be made freely accessible from the curated data archive of ETH Zurich (https://www.research-collection.ethz.ch) under the DOI: 10.3929/ethz-b-000274776.

\section{REFERENCES}

(1) Rhodes, D.; Lipps, H. J. G-Quadruplexes and Their Regulatory Roles in Biology. Nucleic Acids 
Res. 2015, 43 (18), 8627-8637.

(2) Biffi, G.; Tannahill, D.; McCafferty, J.; Balasubramanian, S. Quantitative Visualization of DNA G-Quadruplex Structures in Human Cells. Nat. Chem. 2013, 5 (3), 182-186.

(3) Huppert, J. L.; Balasubramanian, S. G-Quadruplexes in Promoters throughout the Human Genome. Nucleic Acids Res. 2006, 35 (2), 406-413.

(4) Eddy, J.; Maizels, N. Gene Function Correlates with Potential for G4 DNA Formation in the Human Genome. Nucleic Acids Res. 2006, 34 (14), 3887-3896.

(5) Riou, J.-F. G-Quadruplex Interacting Agents Targeting the Telomeric G-Overhang Are More than Simple Telomerase Inhibitors. Curr. Med. Chem. Anticancer. Agents 2004, 4 (5), 439-443.

(6) Gomez, D.; Wenner, T.; Brassart, B.; Douarre, C.; O’Donohue, M.-F.; El Khoury, V.; Shin-Ya, K.; Morjani, H.; Trentesaux, C.; Riou, J.-F. Telomestatin-Induced Telomere Uncapping Is Modulated by POT1 through G-Overhang Extension in HT1080 Human Tumor Cells. J. Biol. Chem. 2006, $281(50), 38721-38729$.

(7) Rodriguez, R.; Müller, S.; Yeoman, J. A.; Trentesaux, C.; Riou, J.-F.; Balasubramanian, S. A Novel Small Molecule That Alters Shelterin Integrity and Triggers a DNA-Damage Response at Telomeres. J. Am. Chem. Soc. 2008, 130 (47), 15758-15759.

(8) Campbell, N.; Collie, G. W.; Neidle, S. Crystallography of DNA and RNA G-Quadruplex Nucleic Acids and Their Ligand Complexes. In Current Protocols in Nucleic Acid Chemistry; John Wiley \& Sons, Inc.: Hoboken, NJ, USA, 2012; p 17.6.1-17.6.22.

(9) Webba da Silva, M. NMR Methods for Studying Quadruplex Nucleic Acids. Methods 2007, 43 (4), 264-277.

(10) Adrian, M.; Heddi, B.; Phan, A. T. NMR Spectroscopy of G-Quadruplexes. Methods 2012, 57 (1), $11-24$.

(11) Li, J.; Correia, J. J.; Wang, L.; Trent, J. O.; Chaires, J. B. Not so Crystal Clear: The Structure of the Human Telomere G-Quadruplex in Solution Differs from That Present in a Crystal. Nucleic Acids Res. 2005, 33 (14), 4649-4659.

(12) Wang, Y.; Patel, D. J. Solution Structure of the Human Telomeric Repeat d[AG3(T2AG3)3] GTetraplex. Structure 1993, 1 (4), 263-282. 
(13) Parkinson, G. N.; Lee, M. P. H.; Neidle, S. Crystal Structure of Parallel Quadruplexes from Human Telomeric DNA. Nature 2002, 417 (6891), 876-880.

(14) Luu, K. N.; Phan, A. T.; Kuryavyi, V.; Lacroix, L.; Patel, D. J. Structure of the Human Telomere in K+ Solution: An Intramolecular $(3+1)$ G-Quadruplex Scaffold. J. Am. Chem. Soc. 2006, 128 (30), 9963-9970.

(15) Phan, A. T.; Kuryavyi, V.; Luu, K. N.; Patel, D. J. Structure of Two Intramolecular G-Quadruplexes Formed by Natural Human Telomere Sequences in K+ Solution. Nucleic Acids Res. 2007, 35 (19), $6517-6525$.

(16) Dai, J.; Carver, M.; Punchihewa, C.; Jones, R. A.; Yang, D. Structure of the Hybrid-2 Type Intramolecular Human Telomeric G-Quadruplex in $\mathrm{K}+$ Solution: Insights into Structure Polymorphism of the Human Telomeric Sequence. Nucleic Acids Res. 2007, 35 (15), 4927-4940.

(17) Lim, K. W.; Amrane, S.; Bouaziz, S.; Xu, W.; Mu, Y.; Patel, D. J.; Luu, K. N.; Phan, A. T. Structure of the Human Telomere in K+ Solution: A Stable Basket-Type G-Quadruplex with Only Two GTetrad Layers. J. Am. Chem. Soc. 2009, 131 (12), 4301-4309.

(18) Wirmer-Bartoschek, J.; Bendel, L. E.; Jonker, H. R. A.; Grün, J. T.; Papi, F.; Bazzicalupi, C.; Messori, L.; Gratteri, P.; Schwalbe, H. Solution NMR Structure of a Ligand/Hybrid-2-GQuadruplex Complex Reveals Rearrangements That Affect Ligand Binding. Angew. Chemie Int. Ed. 2017, 56 (25), 7102-7106.

(19) Chung, W. J.; Heddi, B.; Tera, M.; Iida, K.; Nagasawa, K.; Phan, A. T. Solution Structure of an Intramolecular $(3+1)$ Human Telomeric G-Quadruplex Bound to a Telomestatin Derivative. $J$. Am. Chem. Soc. 2013, 135 (36), 13495-13501.

(20) Redman, J. E. Surface Plasmon Resonance for Probing Quadruplex Folding and Interactions with Proteins and Small Molecules. Methods 2007, 43 (4), 302-312.

(21) Pagano, B.; Mattia, C. A.; Giancola, C. Applications of Isothermal Titration Calorimetry in Biophysical Studies of G-Quadruplexes. Int. J. Mol. Sci. 2009, 10 (7), 2935-2957.

(22) Crothers, D. M. Calculation of Melting Curves for DNA. Biopolymers 1968, 6 (10), 1391-1404.

(23) McGhee, J. D. Theoretical Calculations of the Helix-Coil Transition of DNA in the Presence of Large, Cooperatively Binding Ligands. Biopolymers 1976, 15 (7), 1345-1375. 
(24) Brandts, J. F.; Lin, L. N. Study of Strong to Ultratight Protein Interactions Using Differential Scanning Calorimetry. Biochemistry 1990, 29 (29), 6927-6940.

(25) Rachwal, P. a.; Fox, K. R. Quadruplex Melting. Methods 2007, 43 (4), 291-301.

(26) Mergny, J. L.; Phan, A. T.; Lacroix, L. Following G-Quartet Formation by UV-Spectroscopy. FEBS Lett. 1998, 435 (1), 74-78.

(27) Mergny, J.-L.; Lacroix, L. UV Melting of G-Quadruplexes. In Current Protocols in Nucleic Acid Chemistry; John Wiley \& Sons, Inc.: Hoboken, NJ, USA, 2009; p 17.1.1-17.1.15.

(28) Karsisiotis, A. I.; Hessari, N. M.; Novellino, E.; Spada, G. P.; Randazzo, A.; Webba da Silva, M. Topological Characterization of Nucleic Acid G-Quadruplexes by UV Absorption and Circular Dichroism. Angew. Chem. Int. Ed. Engl. 2011, 50 (45), 10645-10648.

(29) Pagano, B.; Randazzo, A.; Fotticchia, I.; Novellino, E.; Petraccone, L.; Giancola, C. Differential Scanning Calorimetry to Investigate G-Quadruplexes Structural Stability. Methods 2013, 64 (1), $43-51$.

(30) Lim, K. W.; Alberti, P.; Guédin, A.; Lacroix, L.; Riou, J. F.; Royle, N. J.; Mergny, J. L.; Phan, A. T. Sequence Variant (CTAGGG)n in the Human Telomere Favors a G-Quadruplex Structure Containing a G·C·G·C Tetrad. Nucleic Acids Res. 2009, 37 (18), 6239-6248.

(31) Ambrus, A.; Chen, D.; Dai, J.; Jones, R. A.; Yang, D. Solution Structure of the Biologically Relevant G-Quadruplex Element in the Human c-MYC Promoter. Implications for G-Quadruplex Stabilization. Biochemistry 2005, 44 (6), 2048-2058.

(32) Do, N. Q.; Phan, A. T. Monomer-Dimer Equilibrium for the 5'-5' Stacking of Propeller-Type Parallel-Stranded G-Quadruplexes: NMR Structural Study. Chem. - A Eur. J. 2012, 18 (46), 1475214759.

(33) Mergny, J.; Lacroix, L. Analysis of Thermal Melting Curves. Oligonucleotides 2003, 537, 515537.

(34) Gray, R. D.; Chaires, J. B. Analysis of Multidimensional G-Quadruplex Melting Curves. In Current Protocols in Nucleic Acid Chemistry; John Wiley \& Sons, Inc.: Hoboken, NJ, USA, 2011; p 17.4.117.4.16.

(35) Gray, R. D.; Buscaglia, R.; Chaires, J. B. Populated Intermediates in the Thermal Unfolding of the 
Human Telomeric Quadruplex. J. Am. Chem. Soc. 2012, 134 (40), 16834-16844.

(36) Buscaglia, R.; Gray, R. D.; Chaires, J. B. Thermodynamic Characterization of Human Telomere Quadruplex Unfolding. Biopolymers 2013, 99 (12), 1006-1018.

(37) Bončina, M.; Lah, J.; Prislan, I.; Vesnaver, G. Energetic Basis of Human Telomeric DNA Folding into G-Quadruplex Structures. J. Am. Chem. Soc. 2012, 134 (23), 9657-9663.

(38) Marchand, A.; Granzhan, A.; Iida, K.; Tsushima, Y.; Ma, Y.; Nagasawa, K.; Teulade-Fichou, M. P.; Gabelica, V. Ligand-Induced Conformational Changes with Cation Ejection upon Binding to Human Telomeric DNA G-Quadruplexes. J. Am. Chem. Soc. 2015, 137 (2), 750-756.

(39) Marchand, A.; Strzelecka, D.; Gabelica, V. Selective and Cooperative Ligand Binding to Antiparallel Human Telomeric DNA G-Quadruplexes. Chem. - A Eur. J. 2016, 22 (28), 95519555.

(40) Gabelica, V.; Baker, E. S.; Teulade-Fichou, M.-P.; De Pauw, E.; Bowers, M. T. Stabilization and Structure of Telomeric and C-Myc Region Intramolecular G-Quadruplexes: The Role of Central Cations and Small Planar Ligands. J. Am. Chem. Soc. 2007, 129 (4), 895-904.

(41) Marchand, A.; Gabelica, V. Folding and Misfolding Pathways of G-Quadruplex DNA. Nucleic Acids Res. 2016, 44 (22), 10999-11012.

(42) Rosu, F.; De Pauw, E.; Gabelica, V. Electrospray Mass Spectrometry to Study Drug-Nucleic Acids Interactions. Biochimie 2008, 90 (7), 1074-1087.

(43) Benesch, J. L. P.; Sobott, F.; Robinson, C. V. Thermal Dissociation of Multimeric Protein Complexes by Using Nanoelectrospray Mass Spectrometry. Anal. Chem. 2003, 75 (10), 22082214.

(44) Wang, G.; Abzalimov, R. R.; Kaltashov, I. A. Direct Monitoring of Heat-Stressed Biopolymers with Temperature-Controlled Electrospray Ionization Mass Spectrometry. Anal. Chem. 2011, 83 (8), 2870-2876.

(45) El-Baba, T. J.; Woodall, D. W.; Raab, S. A.; Fuller, D. R.; Laganowsky, A.; Russell, D. H.; Clemmer, D. E. Melting Proteins: Evidence for Multiple Stable Structures upon Thermal Denaturation of Native Ubiquitin from Ion Mobility Spectrometry-Mass Spectrometry Measurements. J. Am. Chem. Soc. 2017, 139 (18), 6306-6309. 
(46) Hommersom, B.; Porta, T.; Heeren, R. M. A. Ion Mobility Spectrometry Reveals Intermediate States in Temperature-Resolved DNA Unfolding. Int. J. Mass Spectrom. 2017, 419, 52-55.

(47) Alberti, P.; Bourdoncle, A.; Saccà, B.; Lacroix, L.; Mergny, J.-L. DNA Nanomachines and Nanostructures Involving Quadruplexes. Org. Biomol. Chem. 2006, 4 (18), 3383.

(48) Olsen, C. M.; Gmeiner, W. H.; Marky, L. A. Unfolding of G-Quadruplexes: Energetic, and Ion and Water Contributions of G-Quartet Stacking. J. Phys. Chem. B 2006, 110 (13), 6962-6969.

(49) Largy, E.; Mergny, J.-L.; Gabelica, V. Role of Alkali Metal Ions in G-Quadruplex Nucleic Acid Structure and Stability. In The Alkali Metal Ions: Their Role for Life; Sigel, A., Sigel, H., Sigel, R. K. O., Eds.; Springer: Cham, Switzerland, 2016; pp 203-258.

(50) Miyoshi, D.; Karimata, H.; Sugimoto, N. Hydration Regulates Thermodynamics of G-Quadruplex Formation under Molecular Crowding Conditions. J. Am. Chem. Soc. 2006, 128 (24), 7957-7963.

(51) Nakano, S.; Miyoshi, D.; Sugimoto, N. Effects of Molecular Crowding on the Structures, Interactions, and Functions of Nucleic Acids. Chem. Rev. 2014, 114 (5), 2733-2758.

(52) Bertrand, H.; Granzhan, A.; Monchaud, D.; Saettel, N.; Guillot, R.; Clifford, S.; Guédin, A.; Mergny, J.-L.; Teulade-Fichou, M.-P. Recognition of G-Quadruplex DNA by Triangular StarShaped Compounds: With or without Side Chains? Chemistry 2011, 17 (16), 4529-4539.

(53) Largy, E.; Hamon, F.; Rosu, F.; Gabelica, V.; De Pauw, E.; Guédin, A.; Mergny, J.-L.; TeuladeFichou, M.-P. Tridentate N-Donor Palladium(II) Complexes as Efficient Coordinating Quadruplex DNA Binders. Chemistry 2011, 17 (47), 13274-13283.

(54) Bertrand, H.; Bombard, S.; Monchaud, D.; Talbot, E.; Guédin, A.; Mergny, J.-L.; Grünert, R.; Bednarski, P. J.; Teulade-Fichou, M.-P. Exclusive Platination of Loop Adenines in the Human Telomeric G-Quadruplex. Org. Biomol. Chem. 2009, 7 (14), 2864.

(55) Quintana, J. R.; Lipanov, A. A.; Dickerson, R. E. Low-Temperature Crystallographic Analyses of the Binding of Hoechst 33258 to the Double-Helical DNA Dodecamer C-G-C-G-A-A-T-T-C-GC-G. Biochemistry 1991, 30 (42), 10294-10306.

(56) Graves, D. E.; Wadkins, R. M. Thermodynamic Studies of Amsacrine Antitumor Agents with Nucleic Acids. In Molecular Basis of Specificity in Nucleic Acid-Drug Interactions; Pullman, B., Jortner, J., Eds.; Kluwer Academic Publishers: Dordrecht, The Netherlands, 1990; pp 177-189. 
(57) Haq, I.; Ladbury, J. E.; Chowdhry, B. Z.; Jenkins, T. C.; Chaires, J. B. Specific Binding of Hoechst 33258 to the d(CGCAAATTTGCG)2 Duplex: Calorimetric and Spectroscopic Studies. J. Mol. Biol. 1997, 271 (2), 244-257.

(58) Majhi, P. R.; Qi, J.; Tang, C.-F.; Shafer, R. H. Heat Capacity Changes Associated with Guanine Quadruplex Formation: An Isothermal Titration Calorimetry Study. Biopolymers 2008, 89 (4), $302-309$.

(59) Chaires, J. B. Possible Origin of Differences between van't Hoff and Calorimetric Enthalpy Estimates. Biophys. Chem. 1997, 64 (1-3), 15-23.

(60) Bončina, M.; Vesnaver, G.; Chaires, J. B.; Lah, J. Unraveling the Thermodynamics of the Folding and Interconversion of Human Telomere G-Quadruplexes. Angew. Chemie 2016, 128 (35), 1049610500

(61) Gray, R. D.; Trent, J. O.; Chaires, J. B. Folding and Unfolding Pathways of the Human Telomeric G-Quadruplex. J. Mol. Biol. 2014, 426 (8), 1629-1650.

(62) Mashimo, T.; Yagi, H.; Sannohe, Y.; Rajendran, A.; Sugiyama, H. Folding Pathways of Human Telomeric Type-1 and Type-2 G-Quadruplex Structures. J. Am. Chem. Soc. 2010, 132 (42), 1491014918.

(63) Monchaud, D.; Teulade-Fichou, M.-P. A Hitchhiker's Guide to G-Quadruplex Ligands. Org. Biomol. Chem. 2008, 6 (4), 627-636.

(64) Neidle, S. Quadruplex Nucleic Acids as Novel Therapeutic Targets. J. Med. Chem. 2016, 59 (13), 5987-6011.

(65) Bončina, M.; Hamon, F.; Islam, B.; Teulade-Fichou, M.-P.; Vesnaver, G.; Haider, S.; Lah, J. Dominant Driving Forces in Human Telomere Quadruplex Binding-Induced Structural Alterations. Biophys. J. 2015, 108 (12), 2903-2911.

(66) Bončina, M.; Podlipnik, Č.; Piantanida, I.; Eilmes, J.; Teulade-Fichou, M.-P.; Vesnaver, G.; Lah, J. Thermodynamic Fingerprints of Ligand Binding to Human Telomeric G-Quadruplexes. Nucleic Acids Res. 2015, 43 (21), 10376-10386.

(67) Grand, C. L.; Han, H.; Muñoz, R. M.; Weitman, S.; Von Hoff, D. D.; Hurley, L. H.; Bearss, D. J. The Cationic Porphyrin TMPyP4 Down-Regulates c-MYC and Human Telomerase Reverse Transcriptase Expression and Inhibits Tumor Growth in Vivo. Mol. Cancer Ther. 2002, 1 (8), 565- 
(68) Martino, L.; Pagano, B.; Fotticchia, I.; Neidle, S.; Giancola, C. Shedding Light on the Interaction between TMPyP4 and Human Telomeric Quadruplexes. J. Phys. Chem. B 2009, 113 (44), 1477914786

(69) Ofer, N.; Weisman-Shomer, P.; Shklover, J.; Fry, M. The Quadruplex r(CGG)n Destabilizing Cationic Porphyrin TMPyP4 Cooperates with HnRNPs to Increase the Translation Efficiency of Fragile X Premutation MRNA. Nucleic Acids Res. 2009, 37 (8), 2712-2722.

(70) Zamiri, B.; Reddy, K.; Macgregor, R. B.; Pearson, C. E. TMPyP4 Porphyrin Distorts RNA GQuadruplex Structures of the Disease-Associated r(GGGGCC) n Repeat of the C9orf72 Gene and Blocks Interaction of RNA-Binding Proteins. J. Biol. Chem. 2014, 289 (8), 4653-4659.

(71) Morris, M. J.; Wingate, K. L.; Silwal, J.; Leeper, T. C.; Basu, S. The Porphyrin TmPyP4 Unfolds the Extremely Stable G-Quadruplex in MT3-MMP MRNA and Alleviates Its Repressive Effect to Enhance Translation in Eukaryotic Cells. Nucleic Acids Res. 2012, 40 (9), 4137-4145.

(72) Cavaluzzi, M. J.; Borer, P. N. Revised UV Extinction Coefficients for Nucleoside-5'Monophosphates and Unpaired DNA and RNA. Nucleic Acids Res. 2004, 32 (1), e13.

(73) De Cian, A.; Delemos, E.; Mergny, J.-L.; Teulade-Fichou, M.-P.; Monchaud, D. Highly Efficient G-Quadruplex Recognition by Bisquinolinium Compounds. J. Am. Chem. Soc. 2007, 129 (7), 1856-1857.

(74) D’Atri, V.; Porrini, M.; Rosu, F.; Gabelica, V. Linking Molecular Models with Ion Mobility Experiments. Illustration with a Rigid Nucleic Acid Structure. J. Mass Spectrom. 2015, 50 (5), 711-726.

(75) Darby, R. a J.; Sollogoub, M.; McKeen, C.; Brown, L.; Risitano, A.; Brown, N.; Barton, C.; Brown, T.; Fox, K. R. High Throughput Measurement of Duplex, Triplex and Quadruplex Melting Curves Using Molecular Beacons and a LightCycler. Nucleic Acids Res. 2002, 30 (9), e39.

(76) Gabelica, V.; Rosu, F.; De Pauw, E. A Simple Method to Determine Electrospray Response Factors of Noncovalent Complexes. Anal. Chem. 2009, 81 (16), 6708-6715.

(77) Sun, J.; Kitova, E. N.; Wang, W.; Klassen, J. S. Method for Distinguishing Specific from Nonspecific Protein-Ligand Complexes in Nanoelectrospray Ionization Mass Spectrometry. Anal. Chem. 2006, 78 (9), 3010-3018. 

TOC Graphics

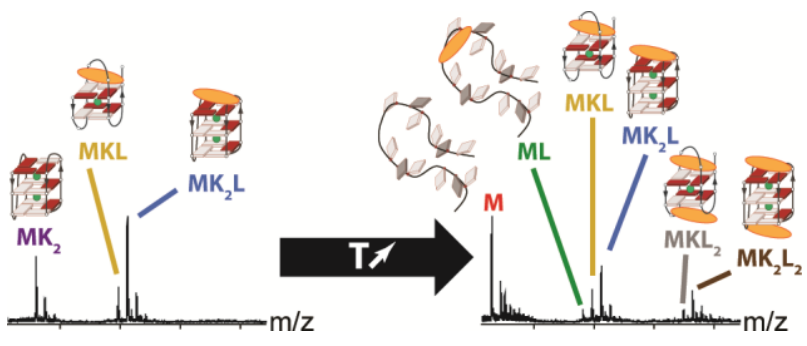

